\title{
1 Empirical wave run-up formula for wave, storm surge and berm width
}

2 Hyoungsu Park*

3 Graduate Research Assistant, School of Civil and Construction Engineering, Oregon State

4 University, Corvallis, OR 97331-2302, USA, Email: hyoungsu.park@gmail.com, Tel: 1-541-

5 602-8618, Fax: 541-737-3052

6 Daniel T. Cox

7 Professor, School of Civil and Construction Engineering, Oregon State University, Corvallis,

8 OR 97331-2302, USA, Email: dan.cox@oregonstate.edu

$9 *$ Corresponding Author

10 Abstract

11 An empirical model to predict wave run-up on beaches considering storm wave and 12 surge conditionsand berm widths (dry beach) have been derived through a synthetic dataset

13 generated from aone-dimensionalBoussinesq wave model.The new run-up equation is

14 expressed as afunction of a new Iribarren number composed of three regions: the foreshore,

15 theberm or dry beach width, and the dune. The dissipative effect ofthe berm is included as a

16 reduction factor expressed as a function of the berm width normalized by the offshore

17 wavelength. The equation is relatively simplebut is shown to be applicable for a fairly wide

18 variety of berm widths and storm wave conditions associated with extreme events such as

19 hurricanes, and itis shown to be an improvement over existingempirical run-up models that

20 do not consider the berm width explicitly. In addition, the new parameterization of the

21 Iribarren number considering the three regions and the berm width reduction factor are shown

22 to improve other empirical models.

23 Keywords: Wave run-up, Surf-similarity parameter, Iribarren number, Boussinesq

24 model, Hurricane, Dune, Berm, Coastal hazards

\section{1. Introduction}

Many cases of inundation and coastal flooding occur during extreme events such as

28 hurricaneswhen the maximum wave run-up exceeds thedune crest. Therefore, the severity of 


\section{Manuscript submitted to Coastal Engineering, Swash-zone Processes}

29 hurricanes can be grossly determined by the relation among the wave and surge conditions

30 and the beach morphology (Sallenger, 2000). Although existing time-dependent numerical

31 models provide accurate, deterministic estimates of wave run-up for given boundary

32 conditions, it is nevertheless necessary to develop simplified expressions for wave run-up that

33 can be used, for example, in probabilistic models for a range of surge and wave forcing and

34 morphological conditions. The complex nature of wave run-up on realistic cross-shore

35 profiles prohibits analytical solutions, so simplified run-up formulas rely on empirical

36 approaches based on field observations (e.g., Holman, 1986)and laboratory experiments (e.g.,

37 Mase, 1989). Few field observationsexist, however, of run-up during extreme storm events

38 (e.g., Senechal et al., 2011), so it is necessary to consider the suitability of these empirical

39 equations for extreme events.

40 Generally, wave run-up is characterized by the Iribarren number, which is also known

41 as the surf-similarity parameter (Battjes, 1974), and is widely utilized for wave run-up on

42 beaches and coastal structures and for tsunami inundation. The Iribarren number is

$43 \quad \xi=\frac{\tan \beta}{\sqrt{H / L}}$

44 where $\beta$ is the angle of thecharacteristic slope, $H$ is the characteristic wave height, and $L$ is the

45 characteristic wavelength. For consistency, we use the nomenclature "Iribarren number"

46 rather than "surf-similarity parameter" because the parameter is also used for coastal

47 structures and tsunamis without surf zones, and we follow the conventional notation of $\xi$.

48 For beaches, $\beta$ is often taken as the angle of the foreshore slope around the still water

49 shoreline, although other values have been used such as the slope at the breakpoint or the

50 mean slope over the active portion of the surf zone. For coastal structures, $\beta$ is generally less

51 ambiguous since rubble mound revetments and breakwater are typically built with a constant

52 slope, usually much steeper than sand beaches. The characteristic wave height is typically the

53 deepwater wave height, $H_{0}$, the wave height at breaking $H_{b}$, or, in the case of coastal 


\section{Manuscript submitted to Coastal Engineering, Swash-zone Processes}

54 structures, the incident wave height at the toe of the structure, $H_{i}$. Similarly, the characteristic

55 wavelength can be the deepwater wavelength $L_{0}=g T^{2} / 2 \pi$, the wavelength at breaking $L_{b}$

56 estimated using linear wave theory and the local water depth at breaking, or the wavelength

57 estimated at the toe of a coastal structure. There are a variety of wave conditions to consider

58 such as regular waves from laboratory studies, irregular waves, and transient waves such as

59 tsunamis. For regular wave studies, $H$ and $T$ are not ambiguous. For the case of irregular

60 waves, $H$ is generally characterized by the significant wave height $H_{s}$, and $T$ is generally

61 characterized by the peak period $T_{p}$, although other characterizations are possible such as

$62 H_{1 / 10}$ or the mean wave period $T_{m}$. For transient wave studies such as for tsunamis modeled as

63 solitary waves, $H$ is generally the maximum positive displacement at a given depth, and $T$ is

64 defined as the duration over which the positive displacement exceeds a certain value, for 65 example.

66 Since Hunt (1959), empirical run-up models have been expressed as a function of the

67 Iribarren number,

$$
\frac{R}{H}=K \xi
$$

where $R$ is the maximum run-up defined as the vertical projection above the still water level,

70 and $K$ is an empirical constant. empirical run-up model on natural beaches using a similar form as Eq. 2 and is given by

$$
\frac{R_{2 \%}}{H_{0}}=0.83 \xi_{f}+0.2
$$

74 wherethe run-up is the value exceeded by $2 \%$ of the run-up events, $R_{2} \%$, normalized by the

75 significant wave height in deepwater. The Iribarren numberis defined using the angle of the

76 foreshore slope $\beta_{f}$, significant wave height in deepwater, and the wavelength in deepwater

77 using the peak wave period: 
78

$$
\xi_{f}=\frac{\tan \beta_{f}}{\sqrt{H_{0} / L_{0}}}
$$

Mase (1989) developed a similar run-up equation based on irregular waves generated

80 in a laboratory on a plane slopes and is written as

81

$$
\frac{R_{2 \%}}{H_{0}}=1.86 \xi_{f}^{0.71}
$$

82 where Eq.4was used to define the Iribarren number in a similar manner as Holman (1986),

83 and the foreshore slope was the same as the slope for the incident waves prior to breaking and 84 ranged from $1 / 30$ to $1 / 5$.

85 Using data sets from US East and West Coast beaches, Stockdon et al. (2006) 86 developed anempirical wave run-up model (hereinafter referred to as the "Stockdon model" 87 for brevity) using an Iribarren-like form given as

$$
R_{2 \%}=1.1\left(0.35 \tan \beta_{f}\left(H_{0} L_{0}\right)^{0.5}+0.5\left[H_{0} L_{0}\left(0.563 \tan \beta_{f}{ }^{2}+0.0004\right)\right]^{0.5}\right)
$$

89 This model is comprised of separate terms to consider different contributions of the wave 90 setup and swash. The swash (the second term on the left hand side of Eq. 6) is further 91 separated into two parts considering incident wave and infra-gravity wave effects. In parallel with the development of empirical equations for wave run-up on beaches,

93 there has been significant development for wave run-up equations oncoastal structures.

94 Unlike studies on beaches, studies of run-up on coastal structures were developed primarily 95 usinglaboratory experiments due, in part, to difficulties of direct measurements on coastal 96 structures during storms. Van der Meer and Stam (1992) provided an empirical run-up 97 equation as piecewise continuous function composed of linear and power curve using the 98 Iribarren number

$$
\frac{R_{2 \%}}{H_{s}}= \begin{cases}0.96 \xi_{m} & \xi_{m}<1.5 \\ 1.17 \xi_{m}{ }^{0.46} & \xi_{m} \geq 1.5\end{cases}
$$




\section{Manuscript submitted to Coastal Engineering, Swash-zone Processes}

100 where $\xi_{m}$ is the Iribarren number defined using the structure slope, $H_{s}$ is the significant wave

101 height of the incident waves at the toe of the structure and, and the subscript $m$ denotes that

102 the wavelength is computed using the mean period. This work was later extended by Waal

103 and Van der Meer (1992) and Van der Meer (1998) to provide a general wave run-up model

104 on dikes to account for the design of the berm, roughness effects of the dike, and wave

105 direction through a combination of reduction factors and is given as

106

$$
\frac{R_{2 \%}}{H_{s}}=1.6 \gamma_{1} \gamma_{2} \gamma_{3} \xi_{p}
$$

107 where the subscript $p$ denotes that Iribarren number is defined using the peak period $T_{p}$. The

108 reduction factor $\gamma$ is a dimensionless number less than 1.0,determined experimentally to

109 account for effects of the berm geometry, $\gamma_{1}$, surface roughness such as natural grass or rock,

$110 \gamma_{2}$, and wave direction, $\gamma_{3}$. This run-up model has an empirical maximum limit of $R_{2 \%} / H_{S}=3.2$

$111 \gamma_{2} \gamma_{3}$

112 Eq. 7 and 8 have been widely adopted for the design of coastal structures, and

113 examples of their application are summarized in coastal engineering manuals (e.g., USACE,

114 2003; Pullen et al., 2007). Similar to run-up models for beaches, some empirical models use

115 slightly different forms of the Iribarren number, particularly when definingthe slope because

116 some revetments and dikes maybe composed of multiple slopes or may include relatively

117 short, flat berms. The need to account for the profile shape was recognized by Saville (1958),

118 and models generally employ an 'equivalent slope' as summarized by Mase et al. (2013).

119 Although tsunamis can occur on vastly different scales compared to wind waves on

120 beaches and coastal structures, the Iribarren number has been found to be a suitable

121 parameter for tsunami run-up studies. For example,Kobayashi and Karjadi (1994) combined

122 numerical model results with laboratoryexperiments to develop an empirical formula to 


\section{Manuscript submitted to Coastal Engineering, Swash-zone Processes}

123 predict the run-up height normalized by theincident solitary wave amplitude $\left(A_{0}\right)$ as a

124 function of Iribarren number, given as

125

$$
\frac{R}{A_{0}}=2.955 \xi^{0.395}
$$

126 where the Iribarren number is defined using a characteristic period for the solitary wave

127 defined as the duration over which the free surface exceeds $0.05 A_{0}$.Kobayashi and Karjadi

128 (1994) show that Eq. 9 is applicable for $0.125<\xi<1.757$ andthat changing the definition of

129 the characteristic period based on exceedance of either $0.01 A_{0}$ or $0.1 A_{0}$ changes the predicted

130 run-up on the order of $10 \%$.

131 The application of Iribarren number for tsunami run-up was analytically studied by

132 Madsen and Furhman (2008), and it highlighted that run-up solutions for the canonical run-up

133 depend on Iribarren number for the non-breaking regular wave.Furthermore,Madsen and

134 Schaffer (2010) provided analytic run-up solutions for the periodic and transient wavesin the

135 termsof the Iribarren number, considering separate breaking and non-breaking regimes. The

136 solutions arethe minimum value between these two terms, given respectively as,

$$
\frac{R}{A_{0}}=\left\{\begin{array}{c}
C_{1} \xi_{1}^{2.0} \\
C_{2}\left(A_{0} / h_{0}\right)^{-0.25} \xi_{1}^{-0.5}
\end{array}\right.
$$

138 where $A_{0}$ is the maximum amplitude of the transient (tsunami) wave modeled using a

139 Gaussian profile and $h_{0}$ is the water depth offshore and can be idealized as the water depth at

140 the continental shelf. For laboratory studies and numerical simulations, $h_{0}$ is typically the

141 water depth in the constant-depth section at the seaward boundary. $C_{1}$ and $C_{2}$ are analytical

142 constantdepending on input wave types (e.g. single wave, $C_{1}=0.1512$ and $C_{2}=4.0513$ ) as

143 discussed in Madsen and Schaffer (2010). The Iribarren number $\xi_{1}$ is defined by a uniform

144 slope, the amplitude of the single wave $A_{0}$, and the deep water wavelength based on a

145 representative period. For the case of a single wave which sustains the solitary wave shape 


\section{Manuscript submitted to Coastal Engineering, Swash-zone Processes}

146 but its frequency is independent from depth and amplitude, the representative period is the

147 duration of $0.75 \%$ of the peak amplitude of the wave.

148 Parket al. (2015) compared the analytic solutions of Madsen and Schaffer (2010) with

149 the output of a time-dependent numerical model and found that the run-up in the breaking

150 region was not predicted by Eq. 10, and that the run-up in the non-breaking region was

151 predicted by Eq. 10 only when bottom friction was not included. Park et al. (2015) used data

152 generated by the time-dependent model to modifythe solutions of Madsen and Schaffer (2010)

153 by separating the domaininto three regimes (breaking, transition, and non-breaking). Further,

154 Park et al. (2015) defined an offshore and onshore Iribarren number to account for large

155 differences between the bathymetric and topographic slopes, and they also accounted for the

156 effects of bottom friction and breaking numerically which were not possible in the analytical

157 treatment of Madsen and Schaffer (2010). The empirical model of Park et al. (2015) is

158 expressed as the minimum of three terms for the breaking, transition, and nonbreaking

159 regions, respectively, as

160

$$
\frac{R}{A_{0}}=\left\{\begin{array}{c}
1.2 \gamma \xi_{1}^{0.5} \\
2.5 \gamma \\
4.0\left(A_{0} / h_{0}\right)^{-0.25} \gamma \xi_{1}^{-0.5}
\end{array}\right.
$$

161 where $h_{0}$ is the $100 \mathrm{~m}$ water depth, $\xi_{1}$ is the offshore Iribarren number defined using the mean

162 slope from the $100 \mathrm{~m}$ depth to the shoreline, the amplitude $A_{0}$, and the deep water wavelength

163 defined as theduration a positive wave train exceeding $1 \%$ of the maximum amplitude. The

164 empirical constant $\gamma$ wasderived from the numerical simulationsand depends on the onshore

165 Iribarren number $\left(\xi_{2}\right)$ and is given as

166

$$
\gamma=[0.9,1.2,1.6] \text { for }\left[\xi_{2}<1.8,1.8 \leq \xi_{2}<4.5, \xi_{2} \geq 4.5\right]
$$

167 where the onshore slope for $\xi_{2}$ is defined as the average slope from the still water shoreline to 168 the point of maximum run-up. This equation was applied without recalibration and shown to 


\section{Manuscript submitted to Coastal Engineering, Swash-zone Processes}

169 predict the tsunami run-up for the 2011 Tohoku tsunami reasonably well despite the fact that

170 the model was developed using the output of a one-dimensional numerical model.

171 This brief introduction highlights that parameterization of run-up using the Iribarren

172 number is successful across a range of scales including wave run-up on beaches, coastal

173 structures, and tsunamis. However, there remain two salient questions for the application for

174 beaches. First, to what extent are existing run-up formulas affected by the presence of the

175 dune-berm system in the case of high surge and waves? Second, in the absence of field

176 observations during extreme conditions, to what extent can the output of time-dependent

177 numerical models be used to improve parameterizedwave run-up models to account for the

178 extreme surge and berm?

\section{2. Numerical model setup}

181 2.1. Dune-Berm Topography and Foreshore Bathymetry

182 Fig. 1 shows an example of the idealized cross-shore dune-berm-foreshore profile used 183 for this study where $x$ is the horizontal coordinate positive in the seaward direction with $x=0$

184 at the shoreline, and $z$ is the elevation from the still water level $(z=0)$. We developed a

185 simplified dune-berm profile using a berm height $\left(h_{B}\right)$, berm width $\left(W_{B}\right)$, dune height $\left(h_{D}\right)$,

186 and dune width $\left(W_{D}\right)$ based on two assumptions that the berm width is flatand that the dune

187 follows a Gaussian shape. We generated the cross-shore beach profile following the extended

188 equilibrium beach profile of Romańczyk et al. (2005) to avoid the infinite slope at the end of

189 the foreshore slope,specifying the median grain size $\left(D_{50}\right)$ and depth of closure $\left(h_{C}\right)$. For

190 simplicity, we prescribed a flat beach profile for $x>1600 \mathrm{~m}$ and $z<-20 \mathrm{~m}$ since the incident

191 waves are essentially unaffected by the bathymetry for $z<-20 \mathrm{~m}$.

192 The dotted line in Fig. 1b shows the observed cross-shore profile at Fire Island, NY, 193 reported by Kraus and Rosati (1997) and is in good agreement with our idealized dune-berm- 
194 foreshore profile with $h_{B}=2.3 \mathrm{~m}, W_{B}=75 \mathrm{~m}, h_{D}=3.7 \mathrm{~m}$, and $W_{D}=26 \mathrm{~m}$. Our idealized

195 profile was examined using four other dune-berm-foreshore systems listed in Table 1 with

196 berm heights and widths ranging $1.6<h_{B}<3.0 \mathrm{~m}$ and10 $<W_{B}<75 \mathrm{~m}$ and dune heights and

197 widths ranging $2.6<h_{D}<5.5 \mathrm{~m}$ and $26<W_{D}<100 \mathrm{~m}$. A dashed line, parallel to the $S W L$,

198 indicates the storm surge level $(S)$ used for the model. $S$ is the overall increased water level

199 due to wind stress, inverse barometric effects, and Coriolis effects associated with wind 200 driven currents. Sdoes not include wave setup effects due to breaking which are captured 201 separately in the numerical model.
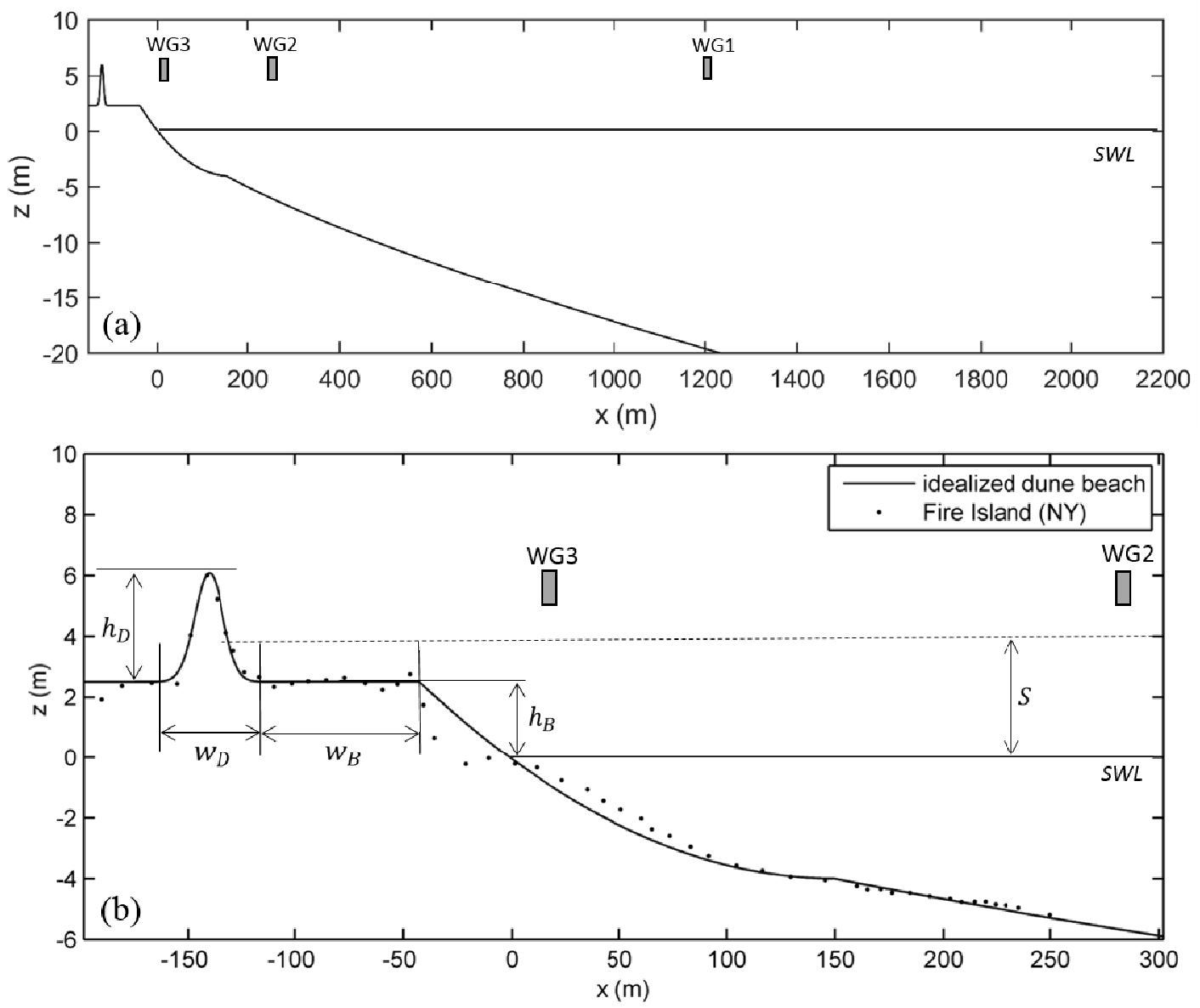

Fig. 1: (a) Idealized cross-shore profile, and (b) and detail of dune-berm-foreshore system. 205

Table 1:Observed dune and berm characteristics. 
Manuscript submitted to Coastal Engineering, Swash-zone Processes

207

208

209

210

211

212

213

214 (2008), and Sandy (2012). Considering only buoy data located near the coast $(z>-50 \mathrm{~m})$, the

215 ranges of observed significant wave heights, $H_{s}$ and peak periods, $T_{p}$ were $2<H_{s}<10$ and 10

$216<T_{p}<17$ (Table 2). For simplicity in our model, we defined the storm surge as a uniform and

217 time-invariant increase in water level and applied it for the range of conditions $0<S<4.0 \mathrm{~m}$.

218 Although a much greater range of conditions are possible for storm surge and waves under

219 extreme hurricane events, this represents a reasonable range for input to the model.

Table 2:Observed hurricanes wave conditions to develop range of input conditions.

\begin{tabular}{lcccc}
\hline Hurricane & Year & Category & $\begin{array}{c}H_{s} \\
{[\mathrm{~m}]}\end{array}$ & $\begin{array}{c}T_{p} \text { or } T_{m} \\
{[\mathrm{~s}]}\end{array}$ \\
\hline Katrina $^{(\mathrm{a})}$ & 2005 & 5 & $2 \sim 6$ & $10 \sim 13$ \\
Gustav $^{(\mathrm{b})}$ & 2008 & 4 & $4 \sim 5$ & $13 \sim 17$ \\
Ike $^{(\mathrm{c})}$ & 2008 & 4 & $4 \sim 6$ & $10 \sim 13^{(\mathrm{e})}$ \\
Sandy $^{(\mathrm{d})}$ & 2012 & 3 & $5 \sim 10$ & $10 \sim 15$ \\
\hline
\end{tabular}




\section{Manuscript submitted to Coastal Engineering, Swash-zone Processes}

226

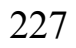

228

229

230

231 address our twoquestions of this study. There are several suitable numerical models based on

232 the nonlinear shallow water wave equations (e.g., Kobayashi and Otta, 1992; Raubenheimer

233 et al., 1995) and Boussinesq equations (e.g., Madsen et al., 1997; Kennedy et al., 2000;

234 Furhman and Madsen, 2008). For this study, we used COULWAVE (Lynett et al., 2002)

235 which solves a set of Boussinesq equations with a higher-order finite-volume methodbecause

236 the model is open source and has been validated through a series of bench mark problems for

237 wave run-up and overtopping and for tsunami inundation using both field and laboratory data

238 (Lynett et al., 2002; Lynett et al., 2003; Lynett and Liu, 2005;Park et al., 2013). For wave

239 breaking, COULWAVE applies the eddy viscosity model which is described in Lynett

240 (2006). The model was applied to study the overtopping problem by Lynett et al. (2010). In

241 this study, the complexity of the overtopping over the irregular cross profiles of leeves were

242 examined during Hurricane Katrina.Park et al. (2015) to develop empirical tsunami run-up

243 equation in a manner similar to that of Kobayashi and Karjadi (1994) as discussed earlier.

244 Because the model has been validated extensively already, we use the model 'as is'

245 without changing the parameters for dissipation due to wave breaking. The model uses

246 anadjustable quadratic bottom friction term with a dimensionless friction factor, $f$, which is

247 typically constant in space and time throughout the simulation. We adjusted the friction factor

248 for the first series of tests as described in the next section, and used the moderate friction

249 value $f=0.02$ for the remainder of the tests. The model grid size was fixed at $1.0 \mathrm{~m}$ for all

250 cases. The run-time of each trial varied from 2,500 to $5,000 \mathrm{~s}$ corresponding to the input 


\section{Manuscript submitted to Coastal Engineering, Swash-zone Processes}

251 wave periods in the range $10<T_{p}<18 \mathrm{~s}$ to assure that we have approximately 250 waves for

252 analysis for each model run. Weutilized the TMA spectral shape with default shape

253 parameters (Bouws et al., 1985) and assumed random phases to develop an input irregular

254 wave condition in the model. Three wave gages (WG1, WG2, and WG3) as shown in Fig. 1

255 were setup at $z=-19.0,-6.0$, and -1.0 mto capture the wave process offshore, in the shoaling

256 region prior to breaking, and in the surf zone after breaking.

257

258 2.4. Model Cases

259

260

261

262

263

264

265

266

267

268

269

270

271

272

273 three median grain sizes, $D_{50}=0.3,0.4$, and $0.5 \mathrm{~mm}$. These values were chosen based on the

$274 D_{50}=0.4 \mathrm{~mm}$ grain size reported in Hanson et al. (2010) for Long Beach, NY, similar to that

275 shown in Figure 1.We note that the profile is fixed and cross-shore sediment transport is not 
Manuscript submitted to Coastal Engineering, Swash-zone Processes

276 considered in this study. Correspondingly, each beach profile had different foreshore slopesin 277 the range $0.023<\tan \beta_{f}<0.091$. The berm height was set as $h_{B}=3.5 \mathrm{~m}$ for all three profiles, and 278 we did not include a dune for Case 1. We usedmoderate wave height conditions $\left(H_{s}=1.0\right.$ and $2792.0 \mathrm{~m})$, but we choose relatively long wave periods $\left(T_{p}=10,12.5,15\right.$, and $\left.17.5 \mathrm{~s}\right)$. No storm 280 surge levels were included $(S=0)$, thus our berm height was high enough that water did not 281 propagate across the flat berm section. Additionally, we tested three different friction 282 coefficients $(f=0.01,0.02,0.03)$ to check the model sensitivity to this parameter.

283

284 Table 3:Summary of model input for Case1.

\begin{tabular}{ccccccc}
\hline Case & $\begin{array}{c}D_{50} \\
{[\mathrm{~mm}]}\end{array}$ & $\begin{array}{c}\tan \beta_{f} \\
{[-]}\end{array}$ & $\begin{array}{c}H_{s} \\
{[\mathrm{~m}]}\end{array}$ & $\begin{array}{c}T_{p} \\
{[\mathrm{~s}]}\end{array}$ & $\begin{array}{c}f \\
{[-]}\end{array}$ & $\begin{array}{c}\text { No. of } \\
\text { Runs }\end{array}$ \\
\hline 1A & 0.3 & 0.023 & $1.0,2.0$ & $10,12.5,15,17.5$ & $0.01,0.02,0.03$ & 24 \\
$1 \mathrm{~B}$ & 0.4 & 0.054 & $1.0,2.0$ & $10,12.5,15,17.5$ & $0.01,0.02,0.03$ & 24 \\
$1 \mathrm{C}$ & 0.5 & 0.091 & $1.0,2.0$ & $10,12.5,15,17.5$ & $0.01,0.02,0.03$ & 24 \\
\hline
\end{tabular}
Note: $h_{B}=3.5 \mathrm{~m}, S=0 \mathrm{~m}, W_{B}=0 \mathrm{~m}, h_{D}=0 \mathrm{~m}, W_{D}=0 \mathrm{~m}$

287 Table 4 summarizes the input conditions forCase 2 . We use only one bathymetry $\left(D_{50}=\right.$ $2880.3 \mathrm{~mm})$ with a corresponding foreshore slope of 0.023 . We addedberm and dune profiles $\left(h_{B}\right.$ $289=2.5 \mathrm{~m}, W_{B}=55 \mathrm{~m}, h_{D}=5 \mathrm{~m}, W_{D}=70 \mathrm{~m}$ ) similar that shown Fig. 1 totestfourstorm surge 290 levels $(S=0.0,1.0,2.0$, and $3.0 \mathrm{~m})$. Incident wave conditions were more typical of hurricane 291 conditions with wave heights and periods in the range $2.0<H_{s}<5.0 \mathrm{~m}$ and $10<T_{p}<18 \mathrm{~s}$. The 292 bottom friction remained fixed at $f=0.02$ forall runs in Case 2.

294 Table 4:Summary of model input for Case 2.

\begin{tabular}{ccccc}
\hline Model case & $\begin{array}{c}S \\
{[\mathrm{~m}]}\end{array}$ & $\begin{array}{c}H_{s} \\
{[\mathrm{~m}]}\end{array}$ & $\begin{array}{c}T_{p} \\
{[\mathrm{~s}]}\end{array}$ & $\begin{array}{c}\text { No. of } \\
\text { Runs }\end{array}$ \\
\hline 2A & 0.0 & $2.0,3.0,4.0,5.0$ & $10,12,14,16,18$ & 20 \\
2B & 1.0 & $2.0,3.0,4.0,5.0$ & $10,12,14,16,18$ & 20 \\
2C & 2.0 & $2.0,3.0,4.0,5.0$ & $10,12,14,16,18$ & 20 \\
2D & 3.0 & $2.0,3.0,4.0,5.0$ & $10,12,14,16,18$ & 20 \\
\hline
\end{tabular}




\section{Manuscript submitted to Coastal Engineering, Swash-zone Processes}

Table 5 summarizes the input conditions for Case 3. Similar to Case 2, we used only one bathymetry $\left(D_{50}=0.3 \mathrm{~mm}\right)$ but we had fiveberm widths $\left(W_{B}=0,25,55,100\right.$, and $\left.200 \mathrm{~m}\right)$. In

298 addition, we simulated surge levels with higher resolution at $0.5 \mathrm{~m}$ increments $(S=1.0,1.5$,

$2992.0 .2 .5,3.0,3.5$, and $4.0 \mathrm{~m}$ ). A slightly lower range of wave heights were tests, $2.0<H_{s}<4.0$

$300 \mathrm{~m}$, but the same range of periods, $10<T_{p}<18 \mathrm{~s}$. Bottom friction was fixed at $f=0.02$. A total of

$301 n=450$ cases were simulated in Case 3, and some of Case 3C overlapped with Case 2.

302

303

304

305

306

307

308

309

310

Table 5:Summary of model input for Case3.

\begin{tabular}{cccccc}
\hline $\begin{array}{c}\text { Model } \\
\text { Case }\end{array}$ & $\begin{array}{c}W_{B} \\
{[\mathrm{~m}]}\end{array}$ & $\begin{array}{c}S \\
{[\mathrm{~m}]}\end{array}$ & $\begin{array}{c}H_{s} \\
{[\mathrm{~m}]}\end{array}$ & $\begin{array}{c}T_{p} \\
{[\mathrm{~s}]}\end{array}$ & $\begin{array}{c}\text { No. of } \\
\text { Runs }\end{array}$ \\
\hline 3A & 0 & $1.0,1.5,2.0,2.5,3.0,4.0$ & $2.0,3.0,4.0$ & $10,12,14,16,18$ & 90 \\
3B & 25 & $1.0,1.5,2.0,2.5,3.0,4.0$ & $2.0,3.0,4.0$ & $10,12,14,16,18$ & 90 \\
3C & 55 & $1.0,1.5,2.0,2.5,3.0,4.0$ & $2.0,3.0,4.0$ & $10,12,14,16,18$ & 90 \\
3D & 100 & $1.0,1.5,2.0,2.5,3.0,4.0$ & $2.0,3.0,4.0$ & $10,12,14,16,18$ & 90 \\
3E & 200 & $1.0,1.5,2.0,2.5,3.0,4.0$ & $2.0,3.0,4.0$ & $10,12,14,16,18$ & 90 \\
\hline
\end{tabular}

Note: $D_{50}=0.3 \mathrm{~mm}, h_{B}=2.5 \mathrm{~m}, h_{D}=5 \mathrm{~m}, W_{D}=70 \mathrm{~m}$.

\section{Wave Run-up Results}

3.1. Case 1: Model Behavior, Run-up Analysis, and Existing Run-up Equations

It is well-known that low frequency motions are generated and amplified as waves propagate across the surf and swash zone (Guza and Thornton, 1982) and that these motions play an important role in wave run-up on beaches (Raubenheimer and Guza, 1996; Ruessink et al., 1998; Ruggiero et al., 2001). Therefore, it is necessary to check that the time-dependent model reproduces these phenomena. Fig. 2a-cshow the spectral energy density of surface elevation in the offshore region, at the shoaling region prior to breaking, and in the surf zone, respectively,for Case $1 \mathrm{~A}$ with $H_{s}=2.0 \mathrm{~m}$, and $T_{p}=12.5 \mathrm{~s}$. The spectra are plotted as a function of normalized frequency, $f^{*}$, defined as $f^{*}=f / f_{p}$, where $f_{p}$ is the peak frequency at WG1, so that $f^{*}=1$ corresponds to the spectral peak of the incident wave spectrum. Fig. 2a-c shows that the low frequency motion is negligible offshore, increases slightly near breaking, 


\section{Manuscript submitted to Coastal Engineering, Swash-zone Processes}

318 and gives a dominant signal in the surf zone. Similar patterns of wave frequency

319 transformation were reported by many researchers (e.g., Cox et al., 1992; Raubenheimer and

320 Guza, 1996), and time-dependent models have been verified to reproduce the correct wave

321 transformation using laboratory and field data. Therefore, we assume that the time-dependent

322 model correctly reproduces the low frequency motions relevant to the processes of wave run-

323 up.

324
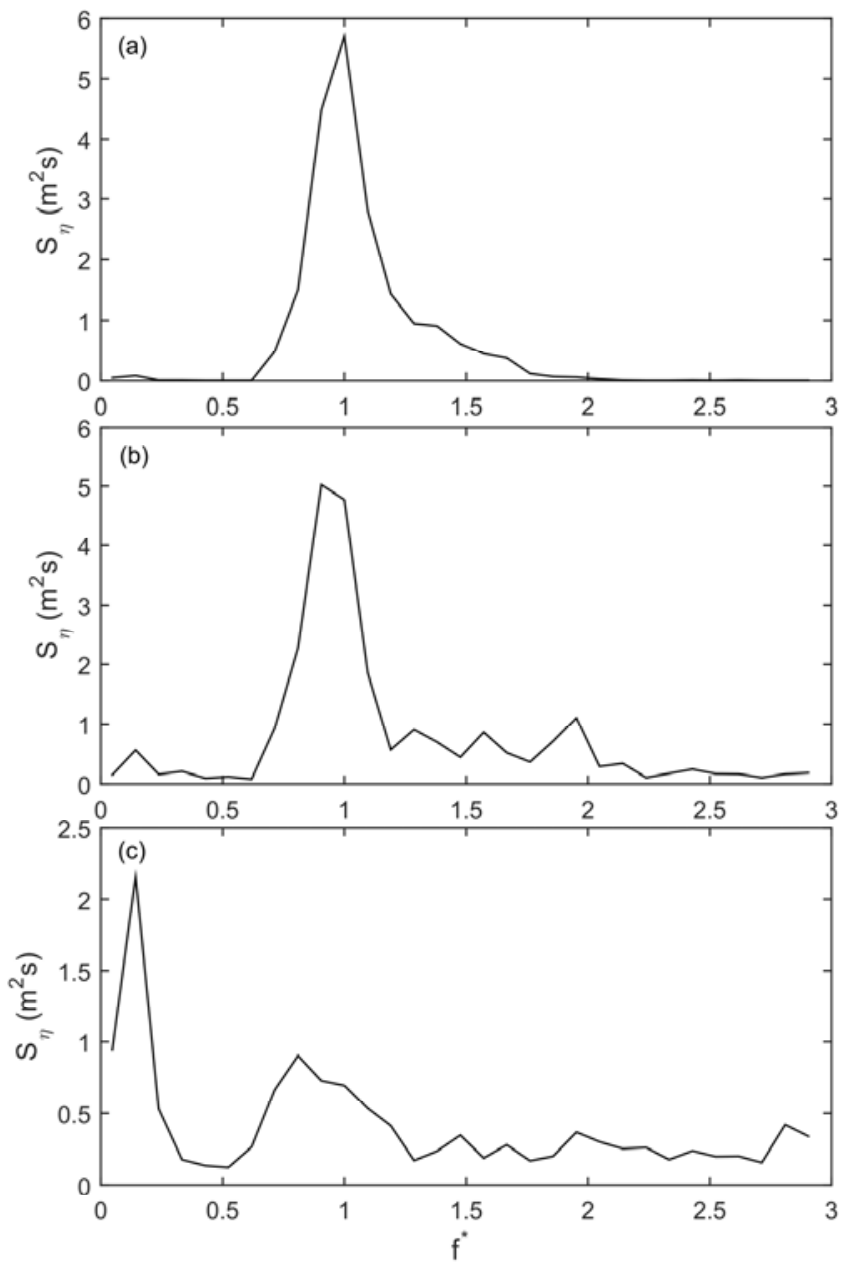

Fig. 2: Spectral densities of surface elevation for Case 1A as a function of normalized frequency, $f^{*}$ at (a) WG1 offshore, (b) WG2 in the shoaling region, and (c) WG3 in the surf zone. 
330 Friction is one of the free parameters that can be adjusted empirically in the numerical

331 model. Higher values of finduce more dissipation during wave propagation and swash run-up,

332 and therefore decrease the run-up. Based on the assumption that the Stockdon model can

333 predict the wave run-up data on the natural beach idealized in Case 1, we compared the

334 Stockdon model with the numerical model results to calibrate the bottom friction as discussed

335 later.
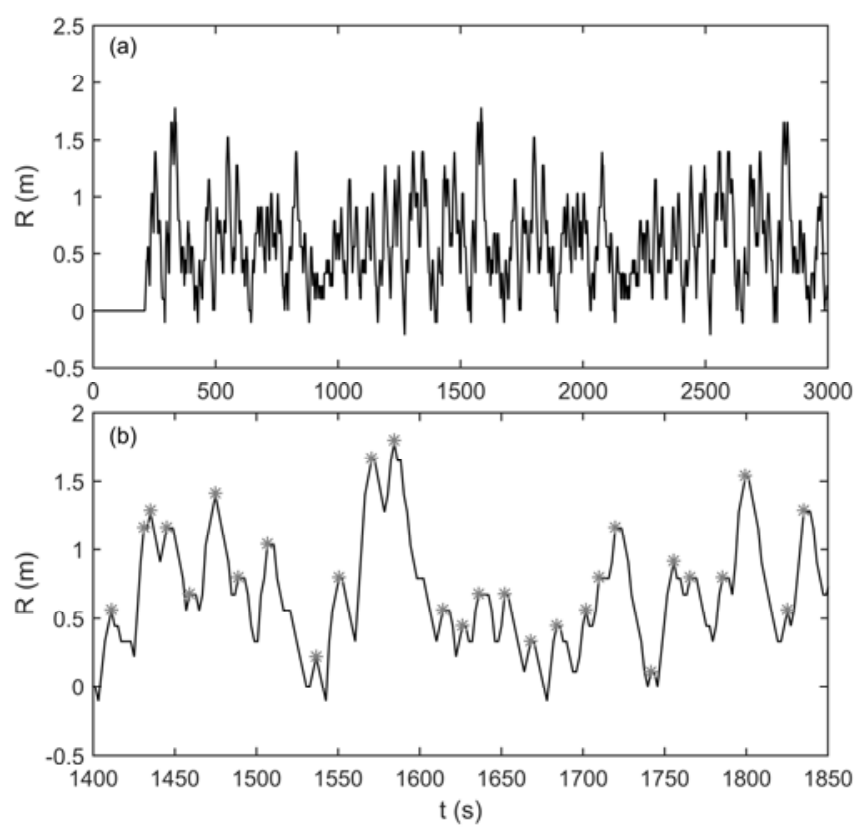

Fig. 3:(a) Run-up for Case 1A, and (b) detail of upper panel. Star symbol indicateslocal run-up maximum.

Fig. 3ashows the time-seriesof the run-up over the entire time series for the same example

342 run shown in Fig. 2, and Fig. 3b shows a detail of the run-up for $1400<t<1850$ s. The stars in

343 Fig. $3 \mathrm{~b}$ are used to indicate the individual run-up maxima. The overall characteristics of the

344 run-up shown in Fig. $3 \mathrm{~b}$ are similar to that for field and laboratory studies, and the total

345 number of run-up maxima for a given run is significantly lower than the number of incident

346 waves owing to surf and swash zone processes such as bore-capture and run-up/rundown 


\section{Manuscript submitted to Coastal Engineering, Swash-zone Processes}

347

348

350

collisions simulated in the time-dependent model. For example, the number of incident waves was 230 , but the total number of run-up maxima was 163 for the case of Fig. 3.

Fig. 4 shows the cumulative probability density function of the run-up where each individual run-up event (marked by a star in Fig. 3b, for example) is plotted as a dot in Fig. 4. Due to the discretization of themodel with approximately $0.11 \mathrm{~m}$ spacing, the run-up events appear in discrete bins along the x-axis. The solid curve is aninterpolationthrough the mean value of each bin. We use this interpolated curve to estimate the following run-up statistics: $R_{\max }$, defined as the maximum run-up height among the individual events; $R_{2 \%}$ defined as the average of the highest $2 \%$ run-up events; $R_{1 / 10}$, the average of highest $1 / 10$ run-up events; and $R_{1 / 3}$, the average of the highest $1 / 3$ run-up events. Of these statistics, we use $R_{2 \%}$ as the representative run-up value for this study to be consistent with earlier studies of extreme runup on beaches (e.g. Holman, 1986; Mase, 1989; Ruggiero et al., 2001; Stockdon et al., 2006) and structures (Van der Meer and Stam, 1992; Van der Meer, 1998; Pullen et al., 2007).

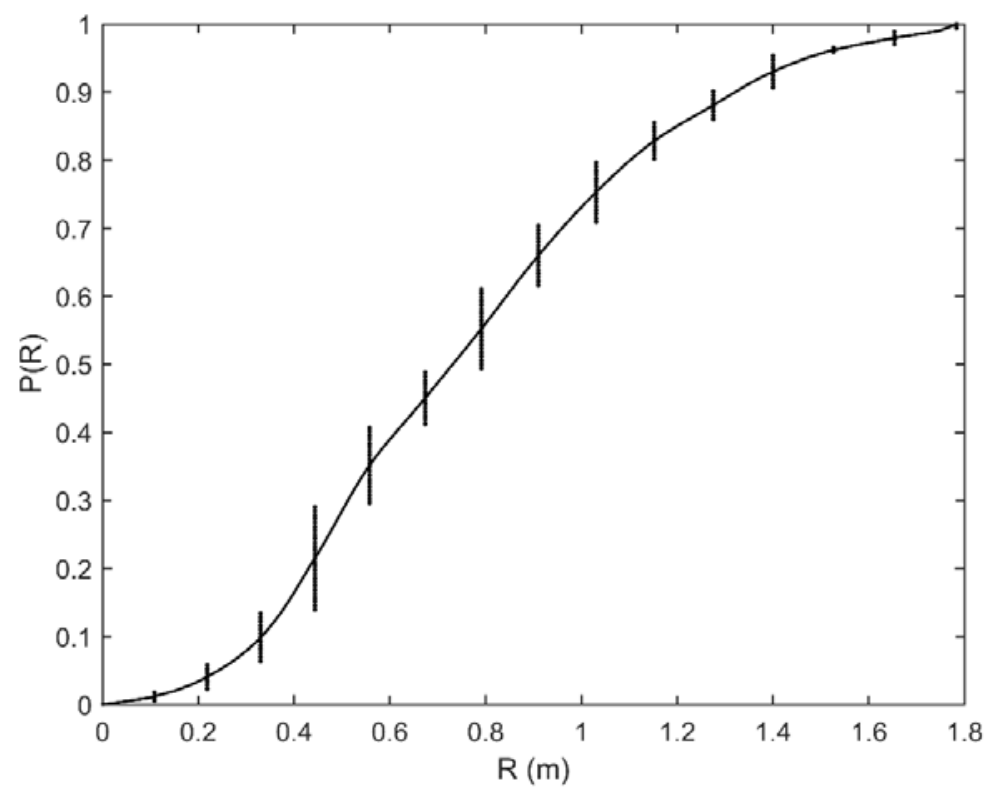

Fig. 4:Cumulative probability density ofwave run-up for Case 1A. Individual run-up events (star symbols in Fig. 3) are plotted as discrete dots and appear as vertical lines in discrete bins. Solid curve is interpolation through the mean of each cluster of dots. 


\section{Manuscript submitted to Coastal Engineering, Swash-zone Processes}

365 Fig. 5 comparesthe numerical data fromCase 1 (symbols) with predictions of the 366 empirical model by theStockdon model (lines). Case 1A (circle), 1B (triangle), and 1C

367 (diamond) show the different foreshore slope condition from mild to steep,and the solid, dash,

368 and dash dot line show corresponding the Stockdon model results. Both the numerical data

369 and the Stockdon model show that $R_{2 \%}$ increases linearly with increasing $\left(H_{0} L_{0}\right)^{0.5}$. The

370 numerical data were generated using a bottom friction $f=0.02$. Comparisons of the data with

371 the Stockdon model for the two other values of bottom friction $(0.01,0.03)$ gave less

372 satisfactory agreement, so $f=0.02$ was adopted for the remainder of this study. This value is

373 reasonable compared to other numerical studies of wave runup on beaches (e.g.Lu et al., 1994;

374 Chen et al., 2000; Lynett, et al., 2002)

375 Fig. 6 showsCase 1 model results (symbols, same notation as Fig. 5), with the run-up 376 normalized by the significant offshore wave height $\left(R_{2} / H_{0}\right)$ plotted as a function of the 377 Iribarren number based on the foreshore slope, $\xi_{f}$, in Eq. 4 . The data for the three different 378 slopes collapse onto nearly a single curve, highlighting the utility of this parameter over the 379 dimensional form $\left(H_{0} L_{0}\right)^{0.5}$. We note that there is still some scatter, due to the nature of using $380 R_{2 \%}$ based on the average of approximately four individual run-up events per run, and plots of $381 R_{\mathrm{s}} / H_{0} \mathrm{vs} \xi_{f}$ and $R_{\mathrm{ave}} / H_{0}$ vs $\xi_{f}$ showed considerably less scatter. The empirical model of 382 Holman (1986) shown by the dash line (Eq. 3) and based on field observations 383 underestimates the normalized run-up, and the model of Mase (1989) based on laboratory 384 observations over a plane slope overestimates the run-up. Nevertheless, we use the general 385 form of these equations (without the $y$-intercept for simplicity) fitted to the numerical data as 386 a function of $\xi_{f}$

$$
\frac{R_{2 \%}}{H_{0}}=1.35 \xi_{f}^{0.65}
$$


388 and use this as a baseline when comparing with the more complicated cases including storm 389 surge and berm width.

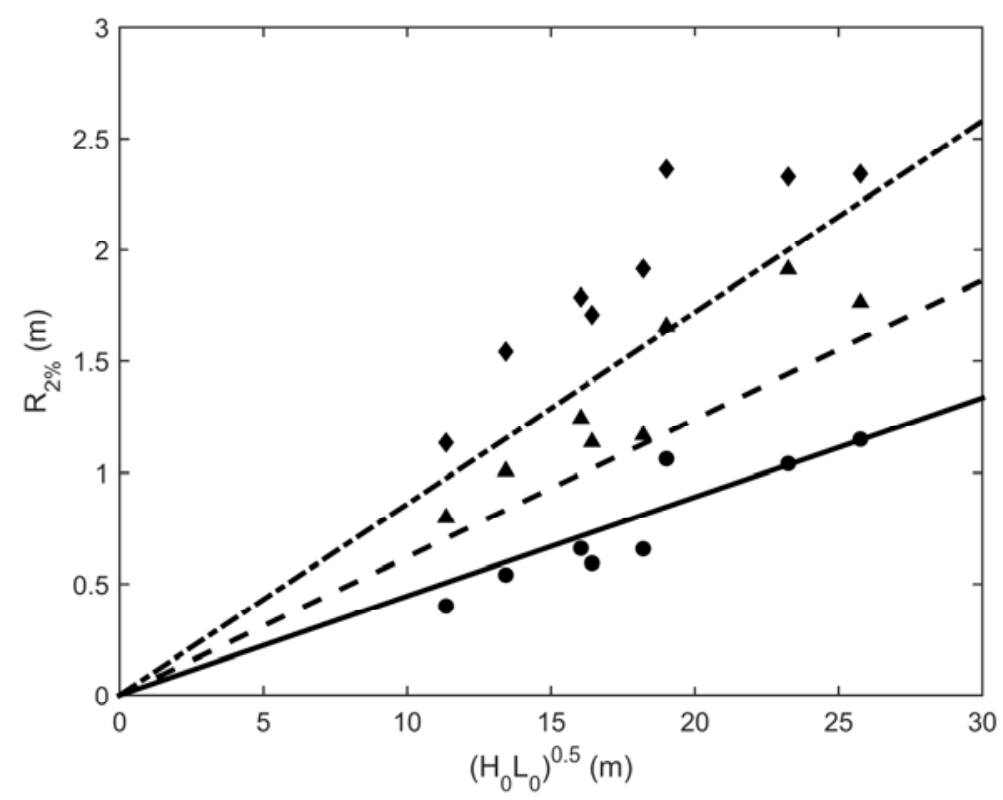

Fig. 5: Run-up comparisons between the numerical model (circle, triangle, diamond) and the Stockdon model (solid, dash, dash-dot) for Case 1A, 1B, 1C, respectively.

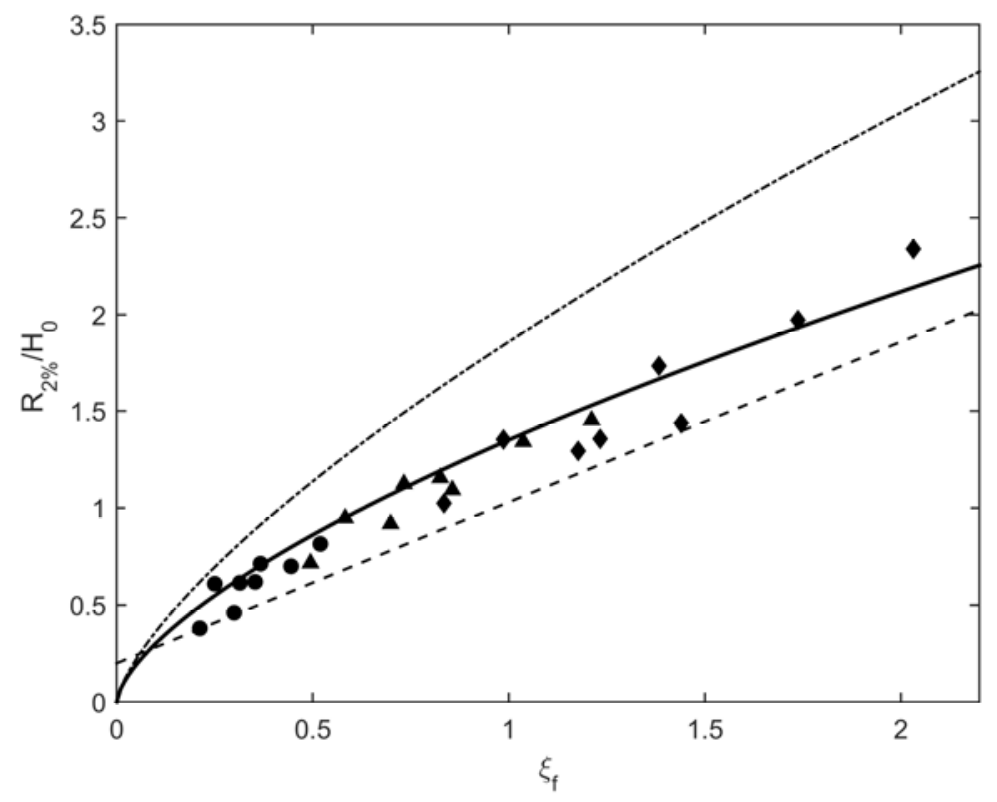

Fig. 6: Comparisons of normalized run-upamong the numerical model for Case 1A (circle), 1B (triangle), 1C (diamond) and models of Holman (dashed), Mase (dash-dot), and Eq. 13 (solid). 


\section{Manuscript submitted to Coastal Engineering, Swash-zone Processes}

398

399

400

401

402

403

404

405

406

407

408

409

410

411

412

413

414

415

416

417

418

419

420

421

422

423

\subsection{Case 2: Run-up with Varying Surge Levels}

For Case 2, we add a dune-berm profile following the idealized cross-shore profile shown in Fig. 1 with $h_{B}=2.5 \mathrm{~m}, W_{B}=55 \mathrm{~m}, h_{D}=5 \mathrm{~m}, W_{D}=70 \mathrm{~m}$, and $\tan \beta_{f}=0.023$ and apply four storm surge levels $(S=0.0,1.0,2.0,3.0 \mathrm{~m})$. In Fig.7, the numerical data show that, for a given value of $\left(H_{0} L_{0}\right)^{0.5}$, the run-up is nearly the same for the first two cases $(S=0.0$ and 1.0 $\mathrm{m})$. For $S=2.0 \mathrm{~m}$, the run-up is in a transition from being foreshore dominant to being dune dominant and there is no clear trend. However, as the surge level increases to $S=3.0 \mathrm{~m}$, the run-up is significantly higher because the run-up is dominated by the dune slopeat this level.Fig. 7 also compares thesenumericaldatato the Stockdon model where the solid line is Eq. 6 using the foreshore slope $\left(\tan \beta_{f}=0.023\right)$ and the dashed line uses the dune slope $\left(\tan \beta_{D}=\right.$ $0.143)$ defined as a dune steepness $\left(2 \mathrm{~h}_{\mathrm{D}} / \mathrm{W}_{\mathrm{D}}\right)$ for simplicity in this study.As expected from the comparison shown in Fig. 5, the Stockdon model agrees with the numerical data when with the surge level is low and the run-up is confined to the foreshore slope. However, the Stockdon model significantly underpredicts the run-up when the surge level is high $(\mathrm{S}=3.0$ m, square symbols). Alternatively, the dashed line shows that the Stockdon model overpredicts all of the numerical data when the dune slope is used. This is likely due to the 55 $\mathrm{m}$ wide dune used for this portion of the study which causes additional wave dissipation.

Fig. 8 shows the data of Fig. 7 replotted as the normalized run-up $R_{2 \%} / H_{0}$ versus the Iribarren number based on foreshore slope $\xi_{f}$. Not surprisinglyfor the cases where the surge level was low and the dry beach width was not a major factor, the model of Holman (dashed) provides a lower bound estimate, the model of Mase (dash-dot) provides an upper bound, and the calibrated model (Eq. 13) provides a reasonable estimate. All of these models underpredictthe highest surge case (square symbols). In summary, Figs. 7 and 8 highlight the shortcomings of existing empirical models to predict extreme run-up with elevated surge over some fixed width of dry beach similar to that shown in Fig. 1. 


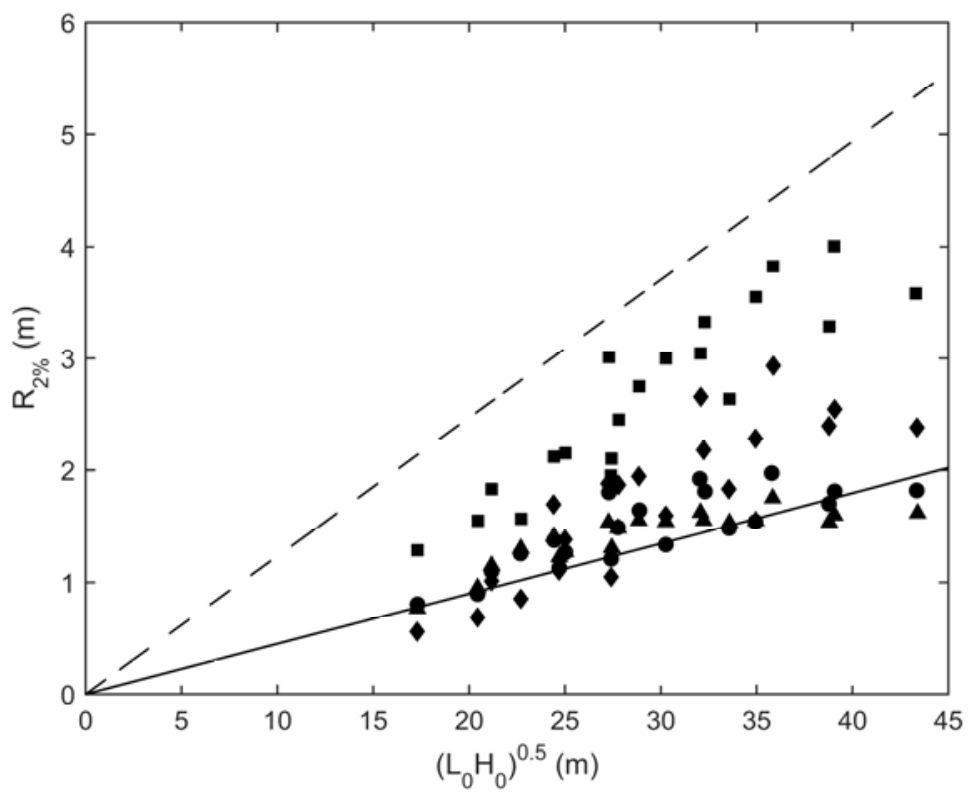

Fig. 7: Run-up for Case 2 considering a range of surge levels. Symbols show numerical model data for $S=0.0 \mathrm{~m}$ (circle), $1.0 \mathrm{~m}$ (triangle), $2.0 \mathrm{~m}$ (diamond), and $3.0 \mathrm{~m}$ (square), andthe Stockdon model uses foreshore slope (solid) and dune slope (dash).

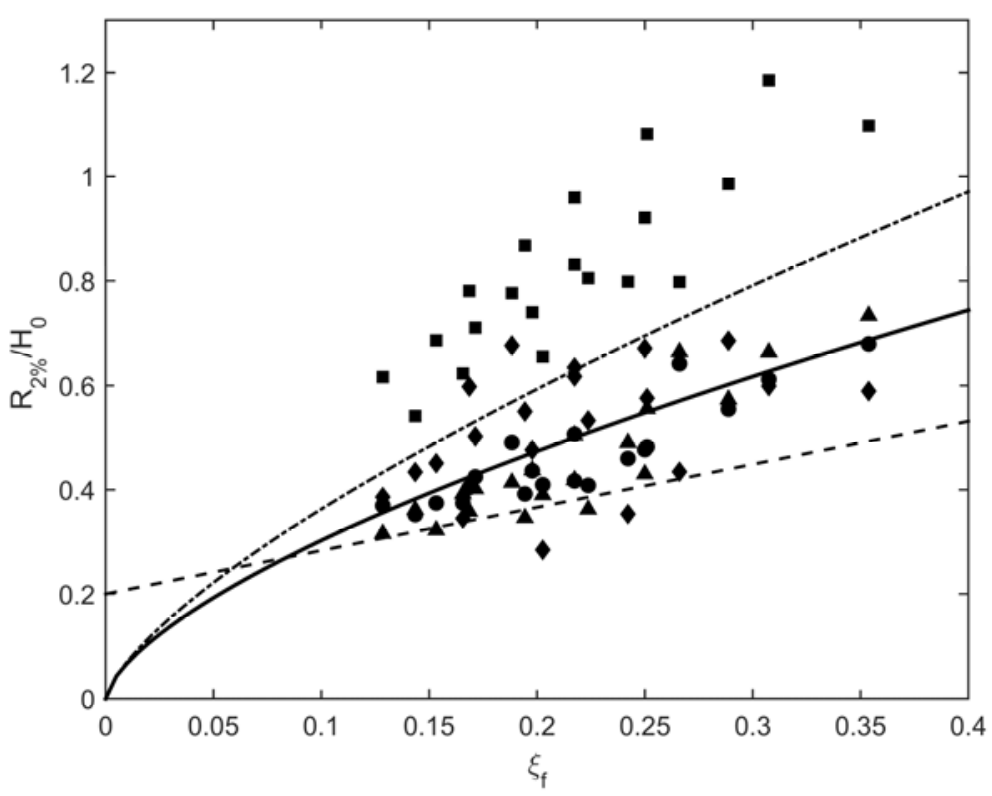

Fig. 8: Normalized run-up for Case 2 considering a range of surge levels. Symbols are

434 3.3. Case3: Considering a Range of Berm Widths and Surge Levels. 
In Case 3 we consider a wide range of berm widths and surge levels to develop a better

436 understanding of how berm width affects wave run-up. Fig. 9 shows the numerical run-up

437 data with circles shaded from black to white for Case $3 \mathrm{~A}\left(W_{B}=0 \mathrm{~m}\right), 3 \mathrm{~B}\left(W_{B}=20 \mathrm{~m}\right), 3 \mathrm{C}$

$438\left(W_{B}=55 \mathrm{~m}\right), 3 \mathrm{D}\left(W_{B}=100 \mathrm{~m}\right)$, and $3 \mathrm{E}\left(W_{B}=200 \mathrm{~m}\right)$. Although there is significant scatter in

439 these data, there is a general trend of a decrease in run-up as the berm width increases. The

440 Stockdon model is shown using the foreshore (solid) and dune (dash) slopes as in Fig. 7. Fig.

4419 shows that the Stockdon model based on the dune slope no longer provides an upper bound

442 to the run-up as several of the run-up values for Case $3 \mathrm{~A}$ with $W_{B}=0 \mathrm{~m}$ exceed the Stockdon

443 model predictions. Similarly, the Stockdon model no longer provides a lower bound based on

444 the foreshore slope, particularly for Cases 3E with berm width is $200 \mathrm{~m}$, noting that it is

445 likely that this condition is beyond the range for which the model was calibratedand less

446 likely to occur on natural beach.

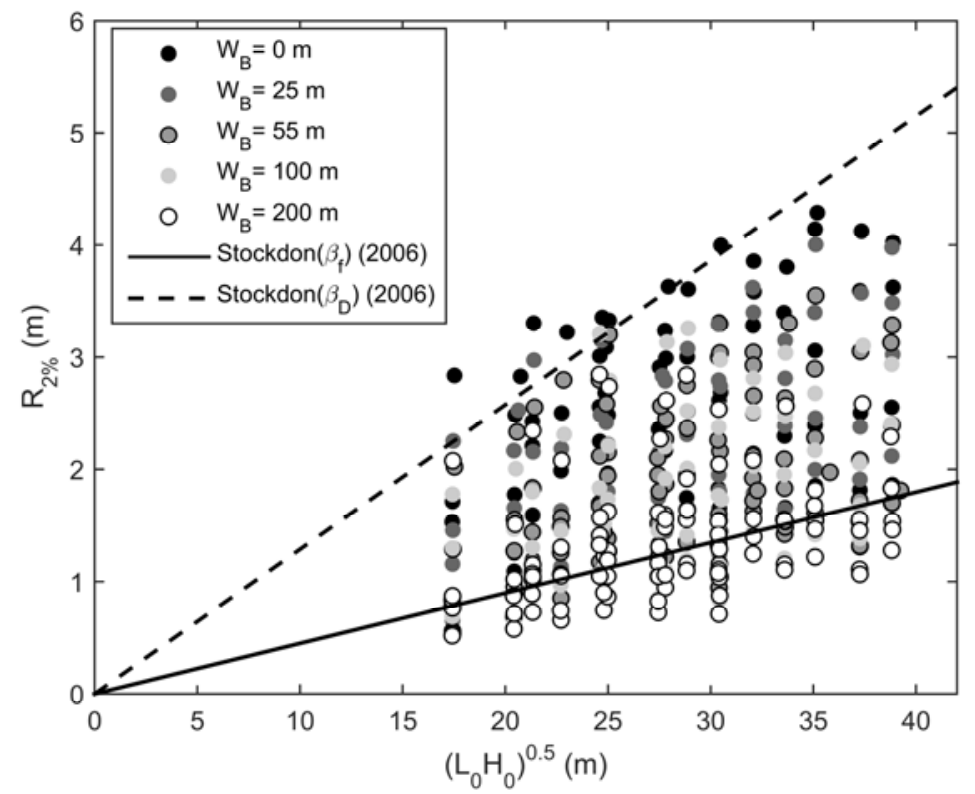

Fig. 9:Run-up for Case 3 with the range of surge and berm widths andthe Stockdon 450 modelusing foreshore (solid) and dune (dash) slopes.

\section{New Empirical Run-up Equation}




\section{Manuscript submitted to Coastal Engineering, Swash-zone Processes}

452 In this section, we developed new run-up equations based on the modeling experience

453 provided by Cases 1 to 3 and on the comparisons with existing empirical formulas. The range

454 of Iribarren number used in Case 1 and Case 3 is only validated for the breaking wave run-up

455 condition $\left(\xi_{f}<2\right)$.In developing this new equation, we kept the general form of Eq. 13 where

456 the run-up is normalized by the significant offshore wave height $\left(R_{2} \% / H_{0}\right)$ and expressed as a

457 function of the Iribarren number. We found it is useful to redefine the Iribarren number based

458 on the foreshore-dune region as explained in Section 4.1 and to introduce a dimensionless

459 reduction factor to account for berm width, similar to the reduction factors used in run-up on

460 coastal structures to account for energy loss due to porous armor stones as explained in

461 Section 4.2.

462

463 4.1.Run-upIribarren Number

464 We consider the cross-shore to be comprised of three regions: (1) the foreshore slope 465 dominant region where the swash occursonly on the beach slope and does not interact with 466 the berm, (2) a transition slope dominant region where the swash occurs at the both foreshore 467 slope and the dune slope regions, and (3) the dune slope dominant region where the swash 468 only occurs at the dune slope. To reflect those three regions, we introduce a new Iribarren 469 number for run-up, $\xi_{R}$ comprised of three parameters $\xi_{f}, \xi_{T}$, and $\xi_{D}$ where the subscripts $f$, $T$, and $470 D$ represent foreshore, transition and dune slope dominant regions, respectively. The 471 boundary of each region depends on the berm height, storm surge level, and deep water wave 472 height and was determined empirically as follows. First, we assume that if the sum of the 473 storm surge level and $70 \%$ of the deep water wave height is less than berm height, then there 474 is no significant wave action over the berm, and the run-up swash is limited primarily to the 475 foreshore slope dominant region. The representative slope anglefor this region is $\beta_{f}$, and the 476 corresponding Iribarren number is $\xi_{f}$. Second, if the storm surge level is greater than the sum 


\section{Manuscript submitted to Coastal Engineering, Swash-zone Processes}

477 of the berm height and $70 \%$ of the deep water wave height (Eq. 14), then we assume that

478 swash motion occurs only on the dune slopedue to the high surge leveland is not impacted by

479 the foreshore slope(Eq. 15). Thus, the representative slope is dune slope, $\beta_{D}$, and the

480 corresponding Iribarren number is $\xi_{D}$. Last, the region between the foreshoreslope and dune

481 slope dominant region is defined as a transition slope dominant regionwhere $\beta_{T}$ is used to

482 represent a fictitious transitions slope which is a combination of both the foreshore slope and 483 dune slope(Eq. 16). The correspondingIribarren number is denoted $\xi_{T}$. Summarizing these 484 definitions, we have

$$
\xi_{f}=\frac{\tan \beta_{f}}{\sqrt{H_{0} / L_{0}}}, \quad \text { for } \quad h_{B}-S \leq 0.7 H_{0}
$$

488 For simplicity, we assume that the transition slope $\beta_{T}$ varies linearly from foreshore to dune 489 slope as the storm surge level changes and is given as

$$
\xi_{D}=\frac{\tan \beta_{D}}{\sqrt{H_{0} / L_{0}}}, \quad \text { for } \quad S-h_{B} \geq 0.7 H_{0}
$$

$$
\xi_{T}=\frac{\tan \beta_{T}}{\sqrt{H_{0} / L_{0}}}, \quad \text { for } \quad-0.7 H_{0}<S-h_{B}<0.7 H_{0}
$$

491 where $\alpha$ increases linearly 0 to 1 as a function of storm surge level, berm height, and wave

492 heightand was found empirically to be

$$
\alpha=\frac{\left(S-h_{B}\right)+0.7 H_{0}}{1.4 H_{0}} \quad, \operatorname{Min}[\alpha]=0 \& \operatorname{Max}[\alpha]=1
$$

where Min and Max are the minimum and maximum value, and $\alpha$ rangesbetween 0 and 1. Eq.

49518 provides a continuous function since $\alpha=0$ at the lowest boundary of the transition region 496 where $S$ - $h_{B}=-0.7 H_{0}$, so that $\beta_{T}=\beta_{f}$. Conversely, $\alpha=1$ at the highest boundary of the transition 497 region where $S-h_{B}=0.7 H_{0}$, and $\beta_{T}=\beta_{D}$. 
499 replace $\xi_{f}$ with $\xi_{R}$. Fig. 10 shows the run-up data from Case 1 and Case 3 plotted against the

500 run-up Iribarrennumber, $\xi_{R}$, where the shaded symbols are same as Fig. 9 to identify the

501 changes in berm width and thethree regions are differentiated as the foreshore slope dominant

502 region (square), transition slope dominant region (triangle), and dune slope dominant region

503 (circle). The solid line presents our fitted curve results applying $\xi_{R}$ to Eq. 13 and works well

504 for the foreshore slope dominant regions (square) and, not surprisingly, provides onlyan

505 upper bound to the rest of the data (triangle, circle) and does not account for the effects of 506 berm width.

507

508

509

510

511

512

\section{4.2. Parameterization of Berm Width}

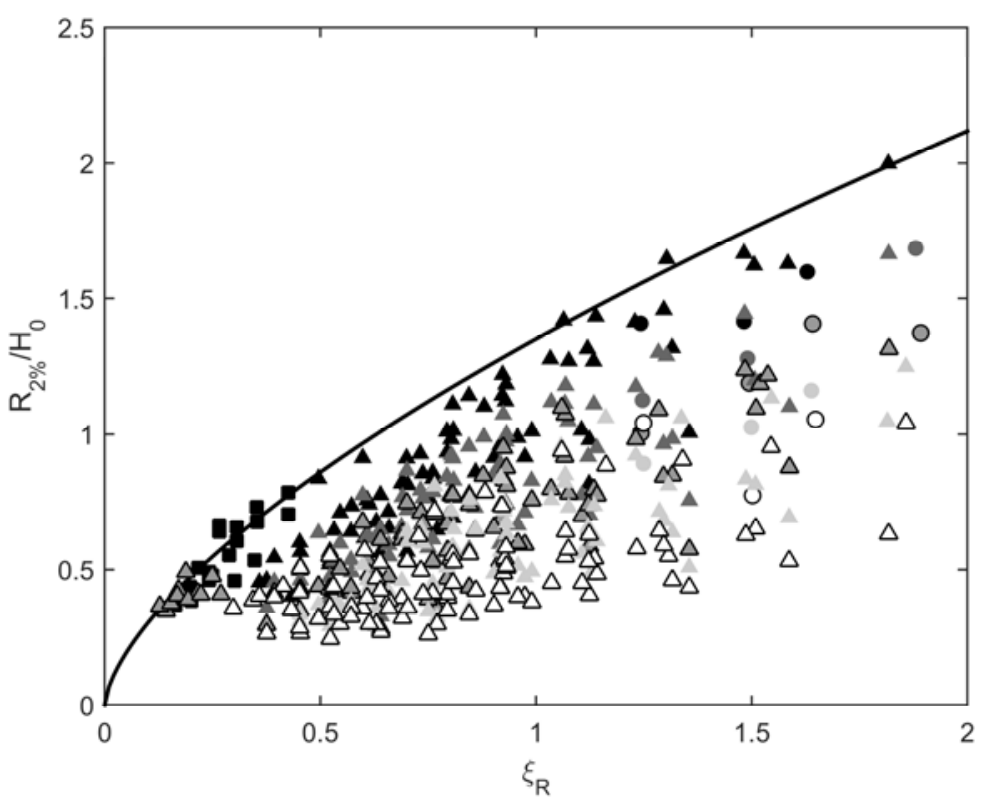

Fig. 10: Normalized run-up for Case1 and Case 3 as a function of $\xi_{R}$ and differentiated as a foreshore (square), transition (triangle) and dune (circle)slope dominant region. Shading to differentiate berm width is the same as Fig. 9. Solid line shows Eq. 13 with $\xi_{R}$. 


\section{Manuscript submitted to Coastal Engineering, Swash-zone Processes}

To incorporate the effect of berm width, we introduce a constant ' $C$ ' as a reduction

515 factor, conceptually similar to that used by Waal and van der Meer (1992) for coastal

516 structures. Our new run-up equation for foreshore-transition-dune slope beach condition is

$$
\frac{R_{2 \%}}{H_{0}}=1.35 C \xi_{R}^{0.65}
$$

518 where $C$ is the reduction coefficient expecting that $C$ is near 1 when the berm width is small

519 and decreases as the berm width increases, and $\xi_{R}$ chosen among $\xi_{f}, \xi_{T}$, and $\xi_{D}$ defined by Eq.

$52014-16$, depending on the geometric conditions of $H_{0}, S$, and $h$. To parameterize $C$ based on

521 berm width and to keep the system of equation dimensionless, we use the offshore

522 wavelength $L_{0}$ as a scaling parameter so that the dimensionless berm width is $W_{B} *=W_{B} / L_{0}$

523 and the functional form is determined empirically from the synthetic data.

524 Fig. 11 shows the numerical run-up data for Case 1 and 3 as a function $W_{B}{ }^{*}$. To

525 develop a suitable curve through these data, we considered the data in bins and computed the

526 mean value (circle) and a more conserve value based on average of all values exceeding the

527 mean for a given bin (triangle). Two curves were fit through the mean and conservative 528 values, and are given by

$$
C=0.8-0.4 \tanh \left(2.0 w_{B}^{*}\right)
$$

$$
C=1.0-0.5 \tanh \left(2.0 w_{B}^{*}\right)
$$

532 and decreases more gradually for $W_{B}^{*}>1.0$ implying that there can be a significant reduction

533 in wave run-up when the berm (dry beach) width is extended from $W_{B}=0$ to $W_{B}=L_{0} / 2$.

534 However, Fig. 11 implies there is relatively little benefit in extending the dry beach width 535 beyond one wavelength for reducing wave run-up for this idealized case that does not 536 consider morphological changes. In any case, the reduction factor $C$ reaches a lower limit of 
538 structures. 555 effects.

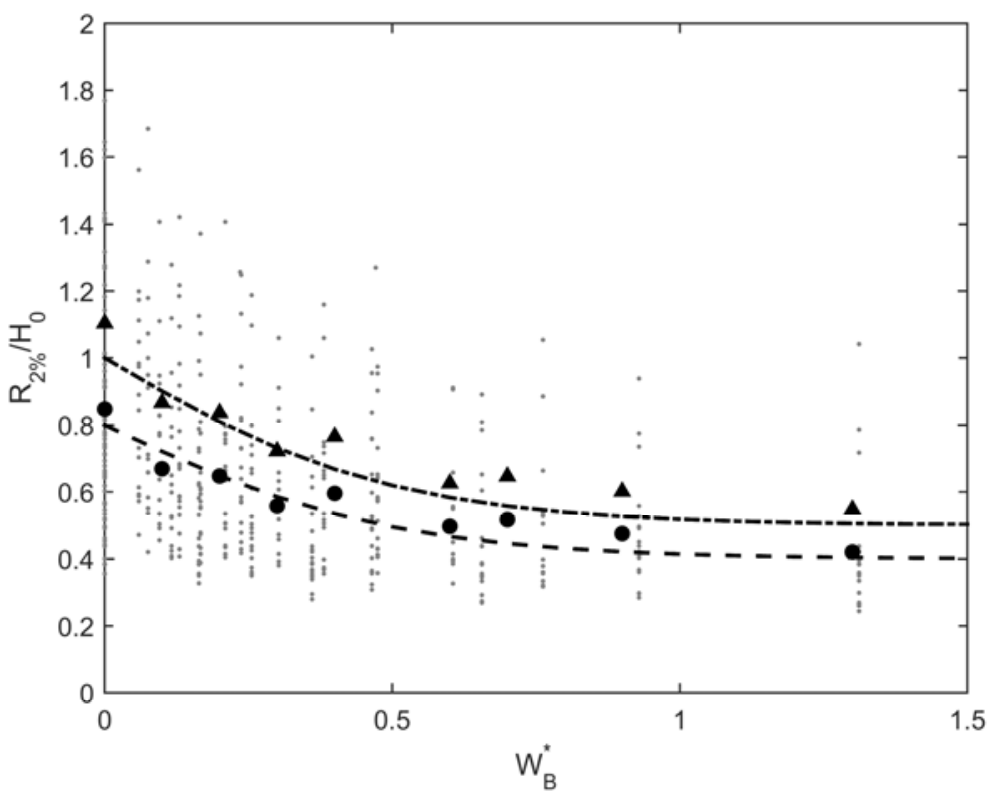

Fig. 11: Dimensionless run-up (dots) as a function of a normalized berm width $\left(W_{B}{ }^{*}\right)$. Mean value (circle) and average of values exceeding the mean (triangle). Curves fitted through large symbols given by Eq. 20 (dash) and Eq. 21 (dash-dot).

Fig. 12a-e shows the normalized run-upplotted as a function of $\xi_{R}$ for the five berm conditions, $W_{B}=0,25,55,100,200 \mathrm{~m}$. For reference, the solid line is Eq. 19 ignoring the effect of the berm width $(C=1)$. The dashed and dash-dot lines include the berm effect with $C$ modeled using the average values (Eq. 20) and are plotted using constant values of $T_{p}=18$ $\mathrm{s}$ and $T_{p}=10 \mathrm{~s}$, respectively, to cover the range of wave periods used to produce the data in each panel. These two lines collapse to a single curve when $W_{B}=0$ (Fig 12a) and are lower than the solid curve because we are using the less conservative Eq. 20 for illustration. In summary, Fig. 12 shows that the functional form of Eq. 19 with the new run-up Iribarren number $\xi_{R}$ and the berm reduction factor based on the berm width normalized by the deep water wavelength (Eq. 20) behaves reasonably well to incorporate storm surge and berm 

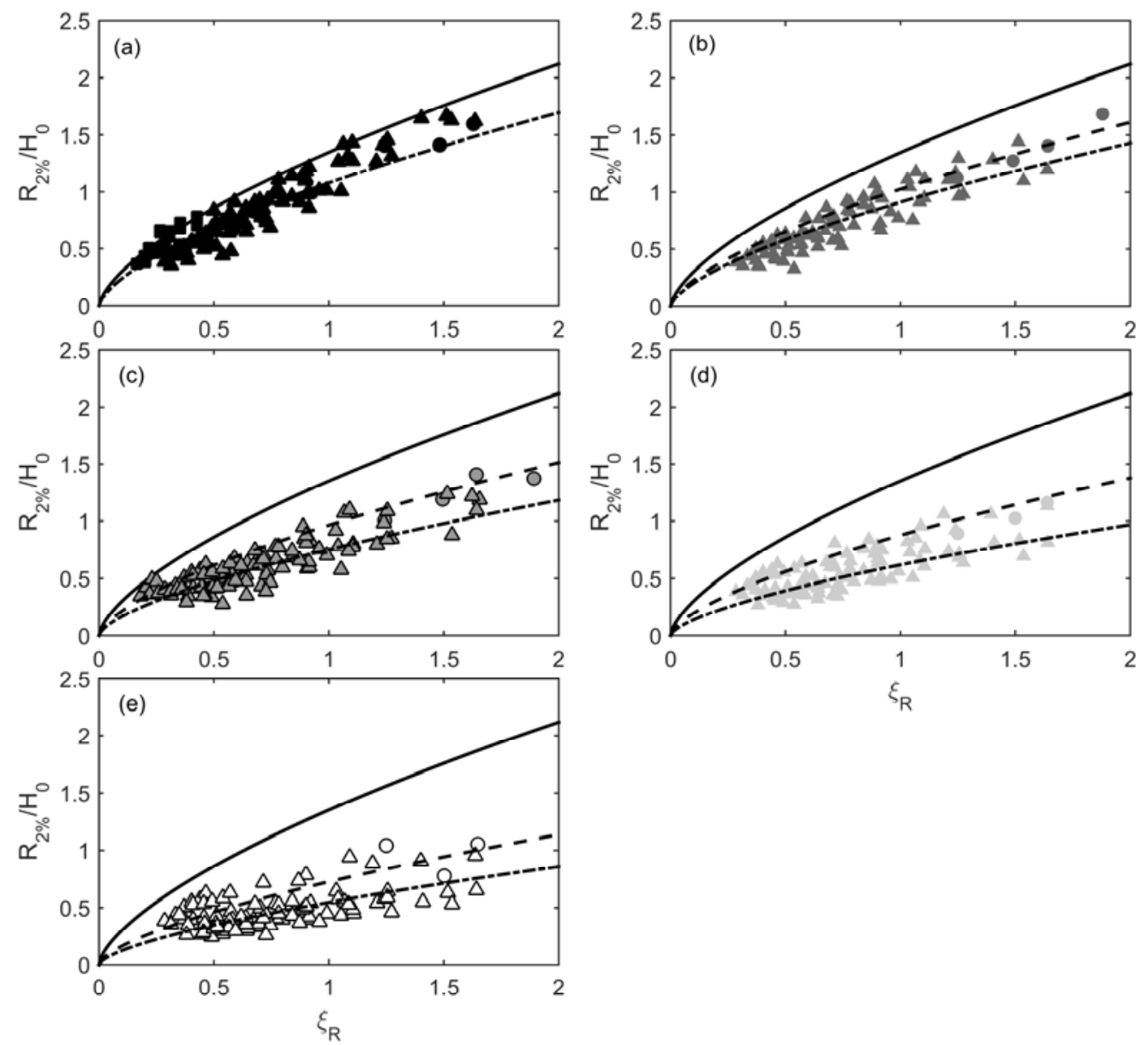

556

557

558

559

560

561

562 563

564 565

566 height $\left(h_{B}\right)$, and wave height $\left(H_{0}\right)$ as given by Eq. 17 and Eq. 18. Also, we propose the 567 modified Stockdon model, version 2 as

Fig. 12. Normalized run-up as a function of a run-up Iribarren number $\left(\xi_{R}\right)$ from Case 3 for the six berm widths (a) $W_{B}=0$, (b) 25, (c) 55, (d) 100, and (e) $200 \mathrm{~m}$. Eq. 19 with $C=$ 1 (solid), Eq. 20 for $T_{p}=18 \mathrm{~s}$ (dash) and $T_{p}=10 \mathrm{~s}$ (dash-dot).

Finally in this section, we note that the original Stockdon model (Eq. 6) can be modified using the ideas developed herein. We propose the modified Stockdon model, version 1, as

$$
R_{2 \%}=1.1\left(0.35 \tan \beta_{R}\left(H_{0} L_{0}\right)^{0.5}+0.5\left[H_{0} L_{0}\left(0.563 \tan \beta_{R}^{2}+0.0004\right)\right]^{0.5}\right)
$$

where the foreshore slope, $\beta_{f}$ of the original equation (Eq. 6) is replaced by a run-up slope, $\beta_{R}$ which represents three slopes conditions, $\beta_{f}, \beta_{T}$, and $\beta_{D}$ depending on the surge level $(S)$, berm 


$$
R_{2 \%}=1.1 C\left(0.35 \tan \beta_{R}\left(H_{0} L_{0}\right)^{0.5}+0.5\left[H_{0} L_{0}\left(0.563 \tan \beta_{R}{ }^{2}+0.0004\right)\right]^{0.5}\right)
$$

569 which adaptsthe berm width reduction factor, $C$.

570 Fig. 13 shows four comparisons of the normalized numerical run-up data from Case 1 571 and Case 3 versusthe run-up predictions from (a) the new model using Eq. 20 for reduction 572 factor, (b) the original Stockdon model (Eq. 6), (c) the modified Stockdon model, version 1 573 (Eq. 22) and (d) the modified Stockdon model, version 2 (Eq. 23) using Eq. 21 for reduction 574 factor. Perfect agreement is shown by the solid line, and the corresponding values of the 575 correlation $\left(\rho^{2}\right)$, root-mean-square error $(R M S E)$ and bias are listed in Table 6 along with 576 values from comparison to the original models of Holman (1986) and Mase (1989).

578 Table 6:Correlation coefficient, RMSE, and bias for model-data comparisons.

\begin{tabular}{cccc}
\hline Model & $\rho^{2}$ & $\begin{array}{c}\text { RMSE } \\
{[\mathrm{m}]}\end{array}$ & $\begin{array}{c}\text { Bias } \\
{[\mathrm{m}]}\end{array}$ \\
\hline New model & 0.74 & 0.135 & 0.028 \\
Stockdon & -8.26 & 0.339 & -0.208 \\
Stockdon, v1 & 0.42 & 0.227 & 0.090 \\
Stockdon, v2 & 0.67 & 0.154 & -0.061 \\
Holman & -91.86 & 0.576 & -0.505 \\
Mase & -17.55 & 0.485 & -0.400 \\
\hline
\end{tabular}

580 Fig. 13a shows that the new model gives satisfactory agreement when compared to the data

581 for which it was calibrated and gives the highest correlation coefficient and lowest RMSE.

582 The original Stockdon model has a negative correlation and large RMSE, indicating that it 583 would provide poor prediction of run-up for the idealized profile shown in Fig. 1 over the 584 range of conditions listed in Table 5. Detailed inspection of the model-data comparison 585 showed that the largest deviation was due to the berm affects not originally included in the 586 Stockdon model. Fig. 13c in which onlyour run-up slope parameterization $\left(\beta_{R}\right)$ is adopted, 587 shows that the first modification to the Stockdon modelslightly overpredicts the run-up (bias 
$588=0.090 \mathrm{~m})$ and provides improvement to the original equation $\left(\rho^{2}=0.42\right)$. Fig. $13 \mathrm{~d}$ in which

589 both our run-up slope parameterization and berm width reduction are adopted, shows that the

590 Stockdon model has the correlation and RMSEa little bit lower than the new model.
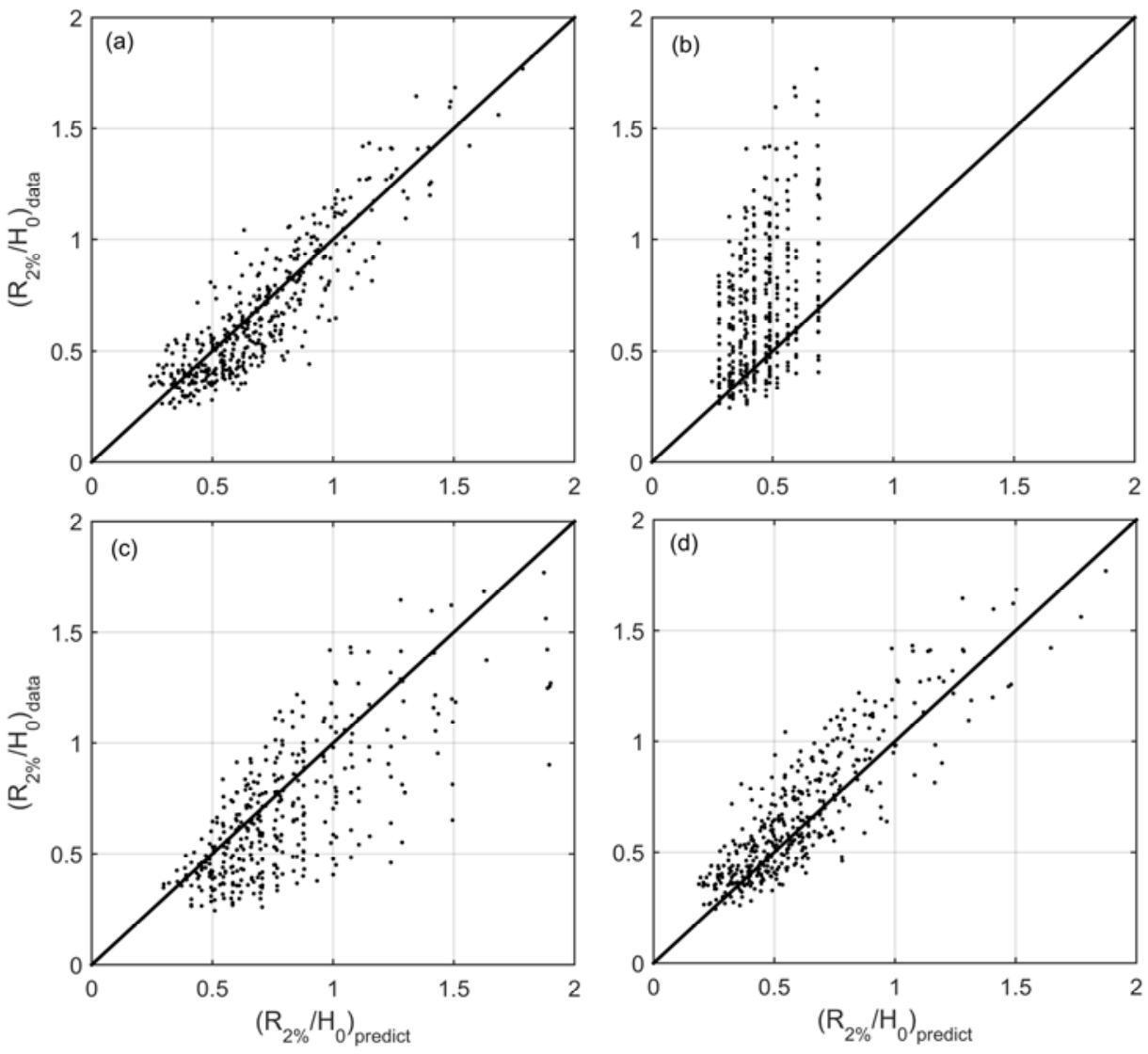

Fig. 13: Comparisons of numerical data with predictions by (a) new equation (Eq. 19), (b) original Stockdon model (Eq. 6), (c) modified Stockdon model v1(Eq. 22), and (d) modified Stockdon model v2(Eq. 23).

598 In this section we acknowledge some of the limitations of our proposed model, discuss the 599 comparisons with the original Stockdon model, and offer some suggestions for improvement. First, our model was developed using synthetic data under fairly idealized cross-shore 601 profile conditions. Although we constructed the morphology using observed profiles (Table 602 1), based the surge and wave forcing conditions on a range of observed conditions (Table 2), 


\section{Manuscript submitted to Coastal Engineering, Swash-zone Processes}

603 and used a time-dependent numerical model to simulate the relevant nearshore processes of

604 breaking, amplification of low frequencies, and swash (Figs. 2, 3), there are limitations to this

605 approach. For example, there is no morphological response in our model, and it is well

606 known that the nearshore morphology responds quickly (on the scale of hours), so that

607 relevant parameters such as foreshore slope and berm width are not constant during large

608 storms. There is no variation in surface roughness in our model. In nature, there is often

609 vegetation or other ecological influences that may change the surface roughness and,

610 therefore, it changes the run-up, particularly over the berm and dune regions impacted by

611 waves and surge only during extreme events. Similarly, we do not include percolation into

612 the sand that may alter the run-up statistics. We limited our analysis to the cross-shore only

613 and included no effects of wave direction. For steep coastal structures, this is particularly

614 important because waves will undergo less refraction. On milder beaches, we anticipate that

615 the waves are generally shore-normal during run-up due to refraction, so we anticipate that

616 wave direction may be less important compared to morphological changes, surface roughness, 617 and percolation.

618 Second, our model has been developed and 'verified' using the same data set. In the

619 future, it will be necessary to use an independent source for model verification through field 620 observations and laboratory testing. We acknowledge that the comparison of our model and 621 the Stockdon model in Fig. 13a and Fig. 13b is limited in some sense because our model was 622 calibrated using the same data for which the comparisons were made and the Stockdon model 623 was calibrated using another data set. On the other hand, the Stockdon model does not 624 include the effects of the berm width explicitly, so it would be unlikely that recalibration of 625 the original Stockdon model to the numerical data would offer much improvement. 1. 626 Third, we show that the Stockdon model can be improved significantly by adopting a 627 new definition of the run-up slope $\left(\beta_{R}\right)$ and by adopting a reduction factor $(\mathrm{C})$ to account for 
628 the berm width.On the other hand, we found that the format of our new equationis simpler 629 and consistent with earlier studies of run-up on beaches, coastal structures and tsunamis.

630 Consistent with these earlier studies, the form of our equation is dimensionless, including the

631 parameterization of the berm width reduction factor. Moreover, the effects of surface

632 roughness, percolation, and other energy losses can easily be incorporated through a series of

633 reduction coefficients, similar to the work of Van de Meer (1998) for coastal structures.

634

\section{6. Conclusion}

636 This study highlights the role of the berm width in affecting wave run-up during 637 extreme surge events and the limitations of existing empirical approaches to predict run-up in 638 these conditions. Using a synthetic data set derived from a time-dependent Boussinesq wave 639 model over an idealized cross-shore profile, we develop a new run-up model using a new run640 up Iribarren number to account for the dune, transition and foreshore dominant regions and 641 utilize a new berm reduction factor parameterized using the berm geometry and offshore 642 wavelength. The main conclusions of this work are:

643 1. Under conditions of hurricane storm surge and waves, the existence of a berm is 644 shown to influence the wave run-up, primarily through dissipation of wave energy 645 across the berm (Fig. 12).

646 2. The empirical wave run-up models of Holman (1986), Mase (1989) and Stockdon 647 et al. (2006) did not compare well with the synthetic data set when the cross-shore 648 profile included a wide berm and a storm surge and waves of typical hurricane 649 conditions (Fig. 13b, Table 6).

650 3. The Iribarren number (Eq. 8) is adequate foam to describe the run-up on beaches 651 with berms under hurricane surge and wave conditions when the Iribarren number 652 is modified to account for the dune, transition and foreshore regions andwhen the 
Manuscript submitted to Coastal Engineering, Swash-zone Processes

653

654

655

656

657

658

659

660

661 the data has been validated over a wide range of nearshore conditions, there are several model

662 simplifications - particularly the lack of a moveable bed - which should be taken into

663 account. Therefore, the new model requires verification through field observations and

664 laboratory testing under hurricane surge and wave condition. In addition, further research is

665 necessary to incorporate effects of coastal vegetation, percolation, and wave direction.

\section{Acknowledgement}

668 This research is based upon work partially supported by the National Science Foundation 669 under Grant No. 1356978. Any opinion, findings, and conclusions or recommendations 670 expressed in this document are those of the authors and do not necessarily reflect the views of 671 the National Science Foundation. The authors thank three anonymous reviewers for their 672 constructive comments. 
Manuscript submitted to Coastal Engineering, Swash-zone Processes

673

674

675

676

677

678

679

680

681

682

683

684

685

686

687

688

689

690

691

692

693

694

695

696

697

698

699

700

701

702

703

704

\subsection{References}

Battjes, J. A., 1974. Surf similarity. Coastal Engineering Proceedings, 1(14), 466-480.

Bouws, E., Gunther, H., Rosenthal, W. and Vincent, C., 1985. Similarity of the Wind Wave Spectrum in Finite Depth Water: 1. Spectral Form.Journal of Geophysical Research: Oceans(1978-2012), 90 (C1) 975 - 986.

Chen, Q., Kirby, J. T., Dalrymple, R. A., Kennedy, A. B., \& Chawla, A., 2000. Boussinesq modeling of wave transformation, breaking, and runup. II: 2D.Journal of Waterway, Port, Coastal, and Ocean Engineering, 126(1), 48-56.

Cox, D. T., Kobayashi, N., and Wurjanto, A., 1992. Irregular wave transformation processes in surf and swash zones. Coastal Engineering Proceedings, 1(23), 156-169.

De Waal, J. P., and Van der Meer, J. W., 1992. Wave run-up and overtopping on coastal structures. Coastal Engineering Proceedings, 1(23), 1758-1774.

Dietrich, J. C., Westerink, J. J., Kennedy, A. B., Smith, J. M., Jensen, R. E., Zijlema, M., et al., 2011. Hurricane Gustav (2008) waves and storm surge: Hindcast, synoptic analysis, and validation in southern Louisiana. Monthly Weather Review, 139(8), 2488-2522.

FDEP (2014) Florida Department of Environmental Protection, Historical Shoreline Database, http://www.dep.state.fl.us/beaches/data/his-shore.htm. Accessed 09/25/2014.

Fuhrman, D. R., and Madsen, P. A., 2008. Simulation of nonlinear wave run-up with a highorder Boussinesq model. Coastal Engineering, 55(2), 139-154.

Guza, R. T., and Thornton, E. B., 1982. Swash oscillations on a natural beach. Journal of Geophysical Research: Oceans (1978-2012), 87(C1), 483-491.

Hanson, H., Larson, M., \& Kraus, N. C., 2010. Calculation of beach change under interacting cross-shore and longshore processes. Coastal Engineering,57(6), 610-619

Hedges, T. S., Reis, M. T., and Owen, M., 1998. Randomwave overtopping of simple sea walls: A new regression model. ICE-Water Maritime and EnergyProceedings, 130(1), 1-10.

Holman, R. A., 1986. Extreme value statistics for wave run-up on a natural beach. Coastal Engineering, 9(6), 527-544.

Hope, M. E., Westerink, J. J., Kennedy, A. B., Kerr, P. C., Dietrich, J. C., Dawson, C., et al., 2013. Hindcast and validation of Hurricane Ike (2008) waves, forerunner, and storm surge. Journal of Geophysical Research: Oceans, 118(9), 4424-4460. 
Manuscript submitted to Coastal Engineering, Swash-zone Processes

705

706

707

708

709

710

Hunt, I. A. (1959). Design of seawalls and breakwaters. Journal of Waterways and Harbours Division, 85, 123-152.

Kennedy, A., Chen, Q., Kirby, J., and Dalrymple, R., 2000. Boussinesq Modeling of Wave Transformation, Breaking, and Runup. I: 1D. Journal of Waterway Port, Coastal and Ocean Engineering, 126(1), 39-47.

Kobayashi, N., and Karjadi, E. A.,1994. Surf-similarity parameter for breaking solitary-wave runup. Journal of waterway, Port, Coastal, and Ocean Engineering, 120(6), 645-650.

Kobayashi, N., Otta, A., and Roy, I., 1987. Wave Reflection and Run-Up on Rough Slopes. Journal of Waterway Port, Coastal and Ocean Engineering, 113(3), 282-298.

Kraus, N. C., and Rosati, J. D., 1997. Interpretation of shoreline-position data for coastal engineering analysis (No. CERC-CETN-II-39). Coastal engineering research center Vicksburg Ms.

Liu, P. L. F., \& Cho, Y. S., 1994. Integral equation model for wave propagation with bottom frictions. Journal of waterway, port, coastal, and ocean engineering, 120(6), 594608.

Lynett, P., Wu, T., and Liu, P., 2002. Modeling wave run-up with depth-integrated equations. Coastal Engineering,46, 89-107.

Lynett, P., Borrero, J., Liu, P. L.-F., and Synolakis, C.E., 2003. Field Survey and Numerical Simulations: A Review of the 1998 Papua New Guinea Tsunami. Pure and Applied Geophysics, 160, 2119-2146.

Lynett, P., and Liu, P. L. F., 2005. A numerical study of the run-up generated by three-dimensional landslides. Journal of Geophysical Research: Oceans (19782012), $110(\mathrm{C} 3)$.

Lynett, P., 2006. Nearshore wave modeling with high-order Boussinesq-type equations. Journal of waterway, port, coastal, and ocean engineering, 132(5), 348-357.

Lynett, P., Melby, J., and Kim, D.-H., 2010.An Application of Boussinesq Modeling to Hurricane Wave Overtopping and Inundation.Ocean Engineering,37, 135-153.

Madsen, P. A., Sørensen, O. R., and Schäffer, H. A., 1997. Surf zone dynamics simulated by a Boussinesq type model. Part II: Surf beat and swash oscillations for wave groups and irregular waves. Coastal Engineering, 32(4), 289-319.

Madsen, P.A. and Fuhrman, D.R., 2008 Run-up of tsunamis and long waves in terms of surfsimilarity. Coastal Engineering. 55, 209-223. 
Manuscript submitted to Coastal Engineering, Swash-zone Processes

737

738

739

740

741

742

743

744

745

746

747

748

749

750

751

752

753

754

755

756

757

758

759

760

761

762

763

764

765

766

767

768

769

Madsen, P. A., and Schaeffer, H. A., 2010. Analytical solutions for tsunami run-up on a plane beach: single waves, N-waves and transient waves. Journal of Fluid Mechanics, 645, $27-57$.

Mase, H., 1989. Random wave run-up height on gentle slope. Journal of Waterway, Port, Coastal, and Ocean Engineering, 115(5), 649-661.

Mase, H., Tamada, T., Yasuda, T., Hedges, T. S., and Reis, M. T., 2013. Wave Runup and Overtopping at Seawalls Built on Land and in Very Shallow Water. Journal of Waterway, Port, Coastal, and Ocean Engineering, 139(5), 346-357.

NDBC (2014) National Data Buoy Center, National Oceanic and Atmospheric Administration, http://www.ndbc.noaa.gov. Accessed 09/26/2014.

NOAA, 2012. Hurricane Research Division: Atlantic Oceanographic and Meteorological Laboratory. Available at: http://www.aoml.noaa.gov/hrd/tcfaq/E11.html

Park, H., Cox, D. T., Lynett, P. J., Wiebe, D. M., and Shin, S., 2013. Tsunami inundation modeling in constructed environments: A physical and numerical comparison of free-surface elevation, velocity, and momentum flux. Coastal Engineering, 79, 9-21.

Park, H., Cox, D. T., and Petroff, C. M., 2015. An empirical solution for tsunami run-up on compound slopes. Natural Hazards, 76 (3), 1727-1743.

Pullen, T., Allsop, N. W. H., Bruce, T., Kortenhaus, A., Sch, H., and Van der Meer, J. W., 2007. Wave overtopping of sea defenses and related structures: assessment manual.

Raubenheimer, B., and Guza, R. T., 1996. Observations and predictions of run-up. Journal of Geophysical Research: Oceans (1978-2012), 101(C11), 25575-25587.

Romańczyk, W., Boczar-Karakiewicz, B., and Bona, J. L., 2005. Extended equilibrium beach profiles. Coastal engineering, 52(9), 727-744.

Ruggiero, P., Komar, P. D., McDougal, W. G., Marra, J. J., and Beach, R. A., 2001. Wave run-up, extreme water levels and the erosion of properties backing beaches. Journal of Coastal Research, 407-419.

Sallenger Jr, A. H., 2000. Storm impact scale for barrier islands. Journal of Coastal Research, 890-895.

Saville, T., 1958. Wave run-up on composite slopes. US Beach Erosion Board.

Senechal, N., Coco, G., Bryan, K. R., and Holman, R. A., 2011. Wave run-up during extreme storm conditions. Journal of Geophysical Research: Oceans (1978-2012), 116(C7).

Stockdon, H. F., Holman, R. A., Howd, P. A., and Sallenger, A. H., 2006. Empirical parameterization of setup, swash, and run-up. Coastal engineering, 53(7), 573-588. 
Manuscript submitted to Coastal Engineering, Swash-zone Processes

770 U.S. Army Corps of Engineers (USACE), 1997. Beach and Nearshore Survey 771 Technology.Coastal Engineering Technical Note, CETN II-38.

772 U.S. Army Corps of Engineers (USACE), 2003.Coastal Engineering Manual.Engineer 773 Manual 1110-2-1110. Washington, DC.

774 Van der Meer, J. W. (1998). Wave run-up and overtopping. Dikes and Revetments: Design, 775 Maintenance and Safety Assessment. ed. KW Pilarczyk (AA Balkema, Rotterdam, 776 The Netherlands), 145-159.

777 Van der Meer, J. W., and Stam, C. J. M., 1992. Wave runup on smooth and rock slopes of 778 coastal structures. Journal of Waterway, Port, Coastal, and Ocean Engineering, $779 \quad 118(5), 534-550$.

780 Wang, D. P., and Oey, L. Y., 2008. Hindcast of waves and currents in Hurricane Katrina. 781 Bulletin of the American Meteorological Society, 89(4), 487-495.

782 
Manuscript submitted to Coastal Engineering, Swash-zone Processes

783 Nomenclature

\begin{tabular}{lll}
\hline Symbol & Descriptions & Unit \\
\hline$D_{50}$ & Median grain size & $\mathrm{L}$ \\
$f_{*}$ & Friction factor & - \\
$f^{*}$ & Normalized frequency & - \\
$H_{0}$ & Deep water wave height & $\mathrm{L}$ \\
$H_{\mathrm{s}}$ & Significant wave height & $\mathrm{L}$ \\
$h_{0}$ & Water depth at the flat bottom & $\mathrm{L}$ \\
$h_{B}$ & Berm height & $\mathrm{L}$ \\
$h_{C}$ & Closer Depth & $\mathrm{L}$ \\
$h_{D}$ & Dune height & $\mathrm{L}$ \\
$L_{0}$ & Deep water significant wave length & $\mathrm{L}$ \\
$P(R)$ & Cumulative probability density of run-up & - \\
$R$ & Run-up & $\mathrm{L}$ \\
$R_{2}$ & Run-up exceed 2\% of the incident waves & $\mathrm{L}$ \\
$R M S E$ & Root mean square error & $\mathrm{L}$ \\
$S$ & Storm surge level (with tide) & $\mathrm{L}$ \\
$S_{\eta}$ & Energy spectrum & $\mathrm{L}{ }^{2} \mathrm{~T}$ \\
$S W L$ & Still water level & $\mathrm{L}$ \\
$T$ & Representative wave period & $\mathrm{T}$ \\
$T_{m}$ & Mean wave period & $\mathrm{T}$ \\
$T_{p}$ & Peak wave period & $\mathrm{T}$ \\
$W_{B}$ & Berm width & $\mathrm{L}$ \\
$W_{B} *$ & Normalized berm width & - \\
$W_{D}$ & Dune width (Dry beach width) & $\mathrm{L}$ \\
$x$ & Distance from the shoreline to seaward & $\mathrm{L}$ \\
$z$ & Elevation from the SWL & $\mathrm{L}$ \\
$A_{0}$ & Tsunami amplitude & $\mathrm{L}$ \\
$\beta_{0}$ & Slop from flat bottom to shoreline & - \\
$\beta_{D}$ & Slop of dune (dune steepness) & - \\
$\beta_{f}$ & Foreshore slope & - \\
$\beta_{R}$ & Run-up slope & - \\
$\beta_{T}$ & Transition slope & - \\
$\xi_{0}$ & Iribarren number (Surf-similarity parameter) & - \\
$\xi_{D}$ & Dune slope Iribarren number & - \\
$\xi_{f}$ & Foreshore slope Iribarren number & - \\
$\xi_{R}$ & Wave run-up Iribarren number & - \\
$\xi_{T}$ & Transition slope Iribarren number & - \\
$\rho^{2}$ & Squared-correlation & - \\
\hline
\end{tabular}

